1964

\title{
Evaluation of lymphangiography
}

F. C. Trimble

University of Nebraska Medical Center

This manuscript is historical in nature and may not reflect current medical research and practice. Search PubMed for current research.

Follow this and additional works at: https://digitalcommons.unmc.edu/mdtheses

Part of the Medical Education Commons

\section{Recommended Citation}

Trimble, F. C., "Evaluation of lymphangiography" (1964). MD Theses. 579.

https://digitalcommons.unmc.edu/mdtheses/579

This Thesis is brought to you for free and open access by the Special Collections at DigitalCommons@UNMC. It has been accepted for inclusion in MD Theses by an authorized administrator of DigitalCommons@UNMC. For more information, please contact digitalcommons@unmc.edu. 
EVALUATION OF LYMPHAIGG IOGRAPHY

F. Cleveland Trimble, III

\author{
Submitted in Partial Fulfillment for the Degree of \\ Doctor of Medicine \\ College of Medicine, University of Nebraska \\ January 27, 1964 \\ Omaha, Nebraska
}




\section{TABLE OF CONTENTS}

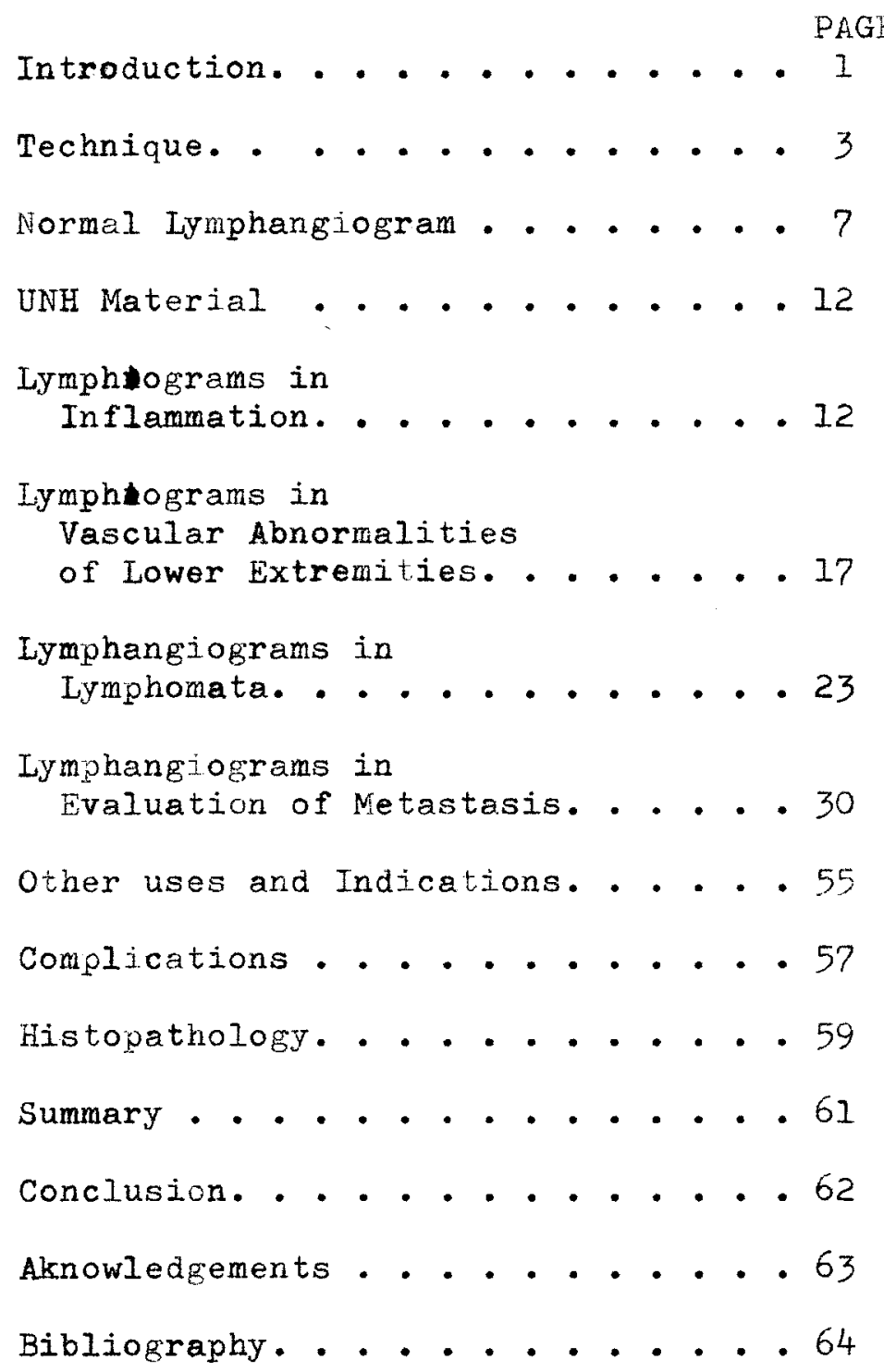


INTRODUCTION:

Radiographic visualization of soft tissue structures in the body is dependent upon the contrast qualities of the tissues and structures which are being studied. In the study of the reticulo-endothelial system a contrast medium must be introduced for radiographic visualization, since this system possesses no inherent contrast characteristics of its own, such as adequate amounts of fat, air, or calcium. The roentgenographic demonstration of lymph vessels and lymph nodes by such means is called lymphangiadenography.

The first attempt to study Iymphatics was made by Nuck in 1692. He injected the lymphatics of cadavers with mercury. Probably the first roentgenographic visualization was made in 1930 by Funaoka, a Japanese investigator, who injected mercury, lead, and iodine salts into the lymph vessels. Carvalho et al., of Portugal, reported radiographic demonstration of lymphatics in 1931 by injecting Thorotrast directly into palpable peripheral lymph nodes in cadavers. Other opaque compounds were used in this manner by Teneff and Stopanni (1932), Shdanow (1932), and Zolotukhin ${ }^{63}(1934)$. Menville and Aré in 1932 injected small amounts of thorium dioxide in the tails and legs of dogs and rats; by injecting as near to blood vessels as possible they were able to visualize nodes with $x$-ray. Menkes in 1932 reported lymphangiographic studies in 
living animals and this was apparently the first to suggest that such might be a potentially useful tool in clinical medicine. Departing from the history of peripheral lymphatic visualization, the first report of radiographic visualization of lymphatics in a living man was apparently made by Pfahler in 1932. He demonstrated radiographically the lymphatic drainage of the maxillary sinuses.

Almost all of the early work was performed in cadavers and animals, with no one devising a practical method which could be used in the investigation of diseases in the human 36,37

Iymphatic system. In 1952, Kinmonth of England first performed Iymphograms in humans and made the major advances leading to our present day techniques. From 1952 many contributions were made and in 1959 a symposium on the subject was held in Nunich at the Ninth International Congress of Radiology. Lymphography can be performed in two ways, direct and indirect. In indirect lymphography the contrast medium is injected into the subcutaneous ${ }^{3}$ or intramuscular tissues adjacent to lymphatics. The most successful use of the indirect method on the extremities has been by Arnulf. ${ }^{2,3}$

The most popular, and apparently best method is the direct injection of the radiopaque medium into the lymphatic vessels (Iymphangiography). This is the method which has been used at the University of Nebraska Hospital since 1960 and is 
the method with which this paper is concerned. The current $3 \% 39$ technique was originally devised by Kinmonth and modified to an applicable form by him in 1955. Further modifications and improvements have been added to the technique by others. 42,53

\section{TECHNIQUE:}

The technique of lyphography used at the University of Nebraska Hospital is basically that described by Kinmonth, $38,3 \%$ with minor modification's. Initially the lymphatics are outlined by injection of $1 \mathrm{ml}$. of $4 \%$ sky Blue dye, mixed with about $0.5 \mathrm{ml}$. of $1 \%$ Xylocaine, subcutaneously into the web of the foot between the first and second phalanges. The patient is then placed comfortably in the supine position on the X-ray table, or on an operating table if portable films are to be taken, and the legs are immobilized. The feet are then given surgical preps and draped. About 30 minutes following injection of the dye, an infiltrating anesthetic is injected and a Iinear incision is made over the dorsum of each foot, along the length of a lymphatic vessel if this can be visualized through the skin; otherwise, along the mid aspect. The dye causes the lymphatics to stand out sharply and they are easily located by their blue color. Upon separation from surrounding tissues, the lymph vessel, according to its size, is cannulated by a 25 to 28 gauge 
polyethylene catheter, which is connected to a control syringe. The contrast medium is then slowly injected into each leg from syringes bilaterally placed in a holding apparatus. The rate of injection is less than $0.5 \mathrm{cc}$ per minute and the total amount injected in each $\mathrm{leg}$ is about $10 \mathrm{cc}$. The rate of injection must be individualized. The ideal injection rate which has been caloulated to be most effective in almost all patients, with the lowest possibility of lymphatic rupture, has been stated to be about $0.12 \mathrm{ml}$. per minute, with the injection time lasting an average of 80 minutes." There have been many devices for controlling the injection rate and at the University of Nebraska Hospital there has been employed a C clamp with a spring, a motor driven injector, manual injection and weights. Of these the most satisfactory was the weights, which weigh 9.5 pounds and are circularly shaped, having a hole in the bottom adapted to fit the plunger of a $20 \mathrm{cc}$. Leur-lok syringe; the plunger must be turned in the barrel every 10 minutes to be sure no stoppage has occurred. It has been recommended that $2 \mathrm{ml}$. be injected as a test dose initially to differentiate from venous injection. Two 35 ways have been described to check this - either a portable film is taken proximal to the injection site to confirm intralymphatic injection, or 20 microcuries of radioactive serum may be injected and a scintillation counter used in the $-4-$ 
inguinal region; there would be a marked difference in circulation time if intravenous injection occurred.

Following injection of the total amount of medium, X-rays are taken of the thigh, inguinal region, and abdomen. Another film is taken in two hours. These initial films visualize the lymphatic vessels. A 24 hour film is then taken which normally shows the lymphatic channels to be free of dye, with the nodes being well visualized at this time. The best procedure is to obtain both antero-posterior, oblique, and lateral films, thus eliminating any possible confusion from overlapping nodes. Frequently with Ethiodol the nodes can be visualized well for 4 - 6 weeks following lymphography, and in some cases this visualization has been noted for more than 8 months." This feature makes it possible to follow node size for some time without repeating the Iymphangiography. The aforementioned method has been used for visualization of the lymphatics in the upper extremities also. In this situation the lymph vessel is cannulated in the "anatomic snuff box" on the distal wrist and only about $6 \mathrm{cc}$. of radiopaque medium is injected. Lymphography of the penis has been performed by others and they suggest cannulation at the medial raphe with injection of only 2 to $4 \mathrm{ml}$. of radiopaque medium. Lymphography in infants and children can be performed'and the amount of radiopaque medium suggested is about $1 / 3$ to $2 / 3$ of 
of the adult dose.

Contrast media most generally accepted now as being 30,54

optimum is Ethiodol - an ethyl ester of iodized poppyseed oil containing $37 \%$ iodine. Best results are obtained when it is warmed. Numerous other forms of contrast media have been used in earlier stages of lymphography, including stannic oxide, thorium dioxide, angiopaque, angiograffin, and many others, including various water soluble iodingted compounds. with the water soluble media visualization of lymphatic channels was adequate to a much lower level than with the oil soluble medium and there was almost no concentration withjn the nodes. A recent addition to the oily contrast media has been a green dye (chlorophyll) which leaves the nodes stained with a green hue, supposedly being a valuable adjunct to the surgeon who performs node dissections. Another innovation which has had poor success has been the perfusion of Iymphatics by Kinmonth's technique with anti-cancer chemotherapeutic agents. It is interesting to note that this failure to have an effect on nodes containing metastatic tumor may have some dependence on the observations and conclusions by others who feel that the lymph nodes have no "filtering" effect on lymphatic drainage and only act as "depots" when functional Iymphoid tissue is present. Nodes involved with malignancy have no ability to act as functional lymphoid tissue. This feeling has stemmed from the fact that with injection of the lymphatics the entire lymphatic chain of the vessels is visualized

$$
-6-
$$


immediately with no visualization of nodes for several hours. However, this still doesn't explain fully the ineffectiveness of the intralymphatic chemotherapeutics.

Although the previously discussed technique, which is used at the University of Nebraska Hospital, is most widely accepted, there are many variations described in the literature, such as different dyes for outlining the lymphatics, different methods of cannulation of the lymphatics, varied apparati for injection, etc..

NORMAL LYMPHANGIOGRAMI:

The normal intralymphatic pressure in the lower extremities is -2 to $-10 \mathrm{~mm}$. of water. Normal Iymphatic flow occurs in waves at 6 to 8 second intervals and correlates with respiration, although it is not synchronous. Injection of a radiopaque medium only minimally distorts the normal pattern when low pressures are used, but the "wave-Iike" motion, as shown with hydrodynamic studies, is no longer in effect.

Lymph channels normally have a uniform diameter throughout their course up the limb, with the diameter being approximately equal to that of a \#27 needle. The lymph vessels closely follow the venous return and bifurcate frequently in their proximal course. Valves are seen at approximately $1 \mathrm{~cm}$. or $-7-$ 
less throughout the channel and there is a spheroid bulge or "beading" at the valve sites. The pathways of the channels in the lower leg are variable, but most frequently the medial lymphatics follow the greater saphenous vein, as do the posteriorly originating channels. Injection of dye on the lateral aspect of the foot reveals the lateral lymphatics curving around the lower $1 / 3$ of the $l e g$ and coursing upward medially. Beginning at the knee there are frequent bifurcations, especially of the vessels medial in origin. There is no intercommunication between the lateral and medial systems. All superficial lymphatics of the fower extremities terminate in the lymph nodes of the superficial inguinal ganglion, which normally has $8-12$ afferent vessels. See Figure I.

Figure I - Medial afferent lymphatics entering the superficial inguinal complex. Note the "beading" at the valve sites.

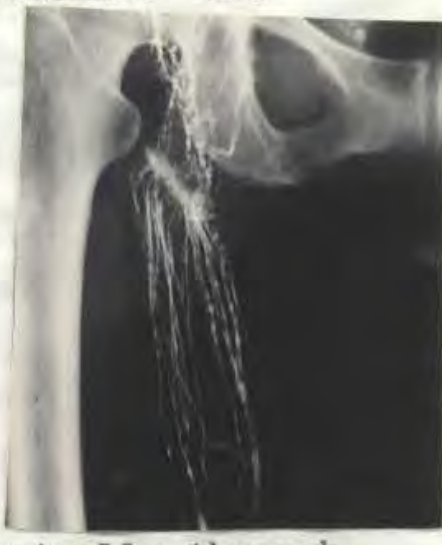

From here a three way current passes proximally through the external and common iliac regions, giving off side chains to the hypogastric group of nodes. These three chains then converge to form a single chain at the lowermost juxtaaorta level. Arriving at the receptaculum chyli, the entire 
channel system converges to form the single thoracic duct. On lateral view the lymphatics adhere to the anterior vertebral border. This unique arrangement of divergence and convergence represents the architecture of the lymphatic system, and distinguishes it from that of the blood circulation. It is stressed that this system is continuous and no nodes are seen to concentrate any dye in the immediate time interval following injection. For this reason it has been suggested that the nodes probably are not filter systems, but act as depots. There has also been demanstration of lymphaticovenous communications by obstruction of a proximal portion of the lymphatic vessel resulting in the dye being shown lowing from lymph vessels into adjacent veins.

The lymphatic channels are shown best immediately following injection of the dye. Normally the channels are cleared of the dye in 24 to 48 hours, with only nodal opacification seen. This contrast medium may then be normally visualized in the nodes for many months. The normal node has a globular or kidney shape, and measures approximately $1.5 \mathrm{~cm}$. in greatest diameter. Normally $8-12$ afferent channels lead into the inguinal complex, with lesser efferents. There is frequently noted a slight indentation at the hilum where the efferents depart. The normal node has a homogeneous reticular pattern with uniform opacification; the normal

$$
-9-
$$


peripheral nodal architecture is smooth and continuous. Oily contrast media is essential for nodal visualization. Herman et al have given a description of the nodes of the ileo-pelvic-aortic Iymphatic systems which correlates very closely to the classical description of this set of nodes by Cuneo and Marcille, and Rouviere. They describe the components of the external iliac group, the hypogastric group, the common iliac group and the abdomino-aortic group. See Figure II. 


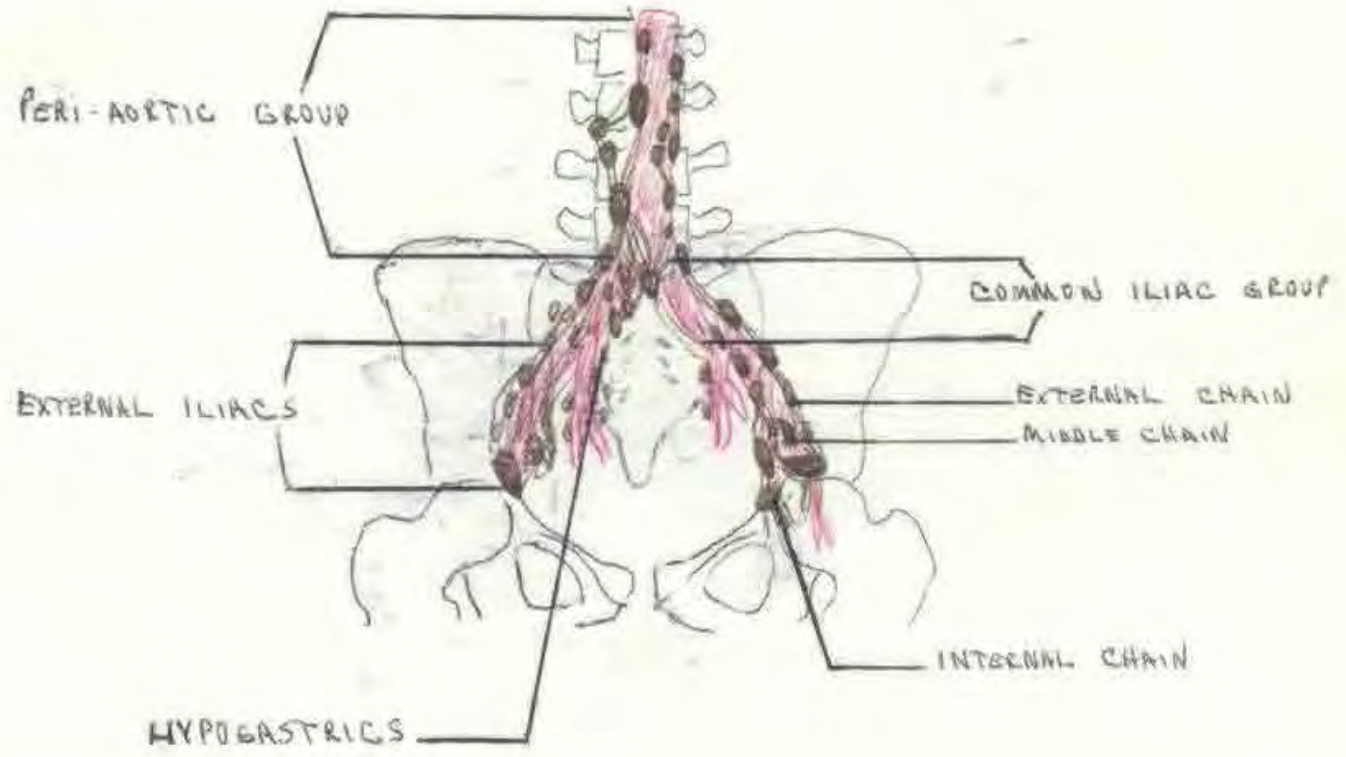

Figure II - Semi-diagrammatic anterior view based on the anatomic studies of Cunéo and Marcille. The three chain arrangement of the iliac groups and the major node groupings are outlined. (From Herman et al) ${ }^{27}$ 
UNH MATERIAL, $1960-1963:$

Lymphography was first employed as a diagnostic tool at the University of Nebraska College of Medicine in 1960. The cases involved in these studies, inclusive to the Autumn of 1963, are herein reviewed, with emphasis on correlation of the patient's physical findings and Iymphangiographic findings. In many cases it has been possible to correlate these findings with histopathologic materials obtained at the operating table or at autopsy.

At the time of this study, all of the lymphangiograms previously performed on these patients were reviewed. Throughout the following case histories, mention will be made of the radiologist's "review" interpretations; these interpretations have been made without the radiologist's knowledge of results of previous histopathologic studies.

Selected photographs of lymphangiograms will be included for illustrative purposes.

\section{LYMPHANGIOGRAMS IN INFLAMMATION:}

The radiographic appearance of 1 mmph nodes involved in an inflammatory process is that of nodal enlargement with the uniform reticular pattern remaining intact. If the inflammatory process is distal to the observed nodes and has been a chronic process, filling defects may be noted which are 
the result of reactive fibrosis. In marked systemic

infections there are sometimes greater numbers of nodes

visualized and they often appear very round or oval. These

changes have been reported in a large number of inflammatory

processes. 57 The following case exemplifies this well.

C.C. \# 1-02-22: This was a 52 year old negro

female admitted for evaluation of a pelvic mass

of five years duration. Pre-operative bilateral

lymphograms revealed continuity of dye in retrograde fashion on both sides, outlining fairly

normal appearing pelvic nodes. There was extention of dye into the iliac and para-aortic

lymphatics, visualizing the nodes in these areas rather well, with the peri-aortic nodes on the left interpreted as being rather large. A large calcific density was noted in the pelvis, which apparently caused some lateral displacement of these nodes to either side of the pelvis. The nodes in the left para-aortic chain were also noticed to be greatly enlarged, and the left kidney had calcific densities. This nodal enlargement was felt to be caused by this chronically infected kidney.

An abdominal hysterectomy was performed with a large leiomyomatous uterus making up the entirety of the surgical specimen. No neoplasm was noted. Films taken slightly over one month following the Iymphograms showed retention of dye with the para-aortic nodes up to the level of T-12. There was also retention of dye within the iliac nodes, with aproximately 25 percent reduction since one month prior. Films taken almost two years later showed no residual dye, but what appeared to be calcific nodes lateral to the third and fourth lumbar vertebratae. These were thought to represent mesenteric nodes.

See Figures III, IV, and V. 


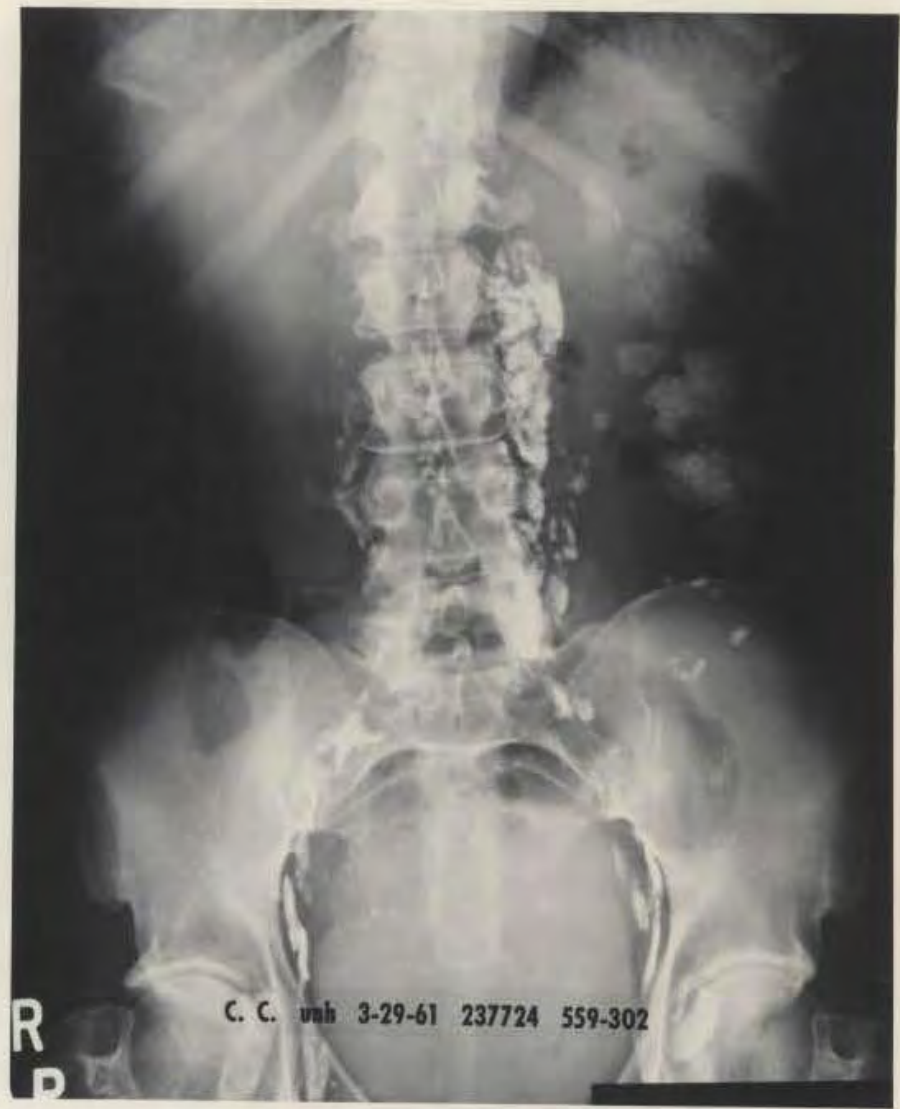

Figure III - Antero-posterior roentgenograph 24 hours following lymphangiography. Note the calcific density in the true pelvis which causes some lateralward displacement of the nodes. Note the greatly enlarged nodes medial to the calcific left kidney, which is probably a chronic source of infection. 


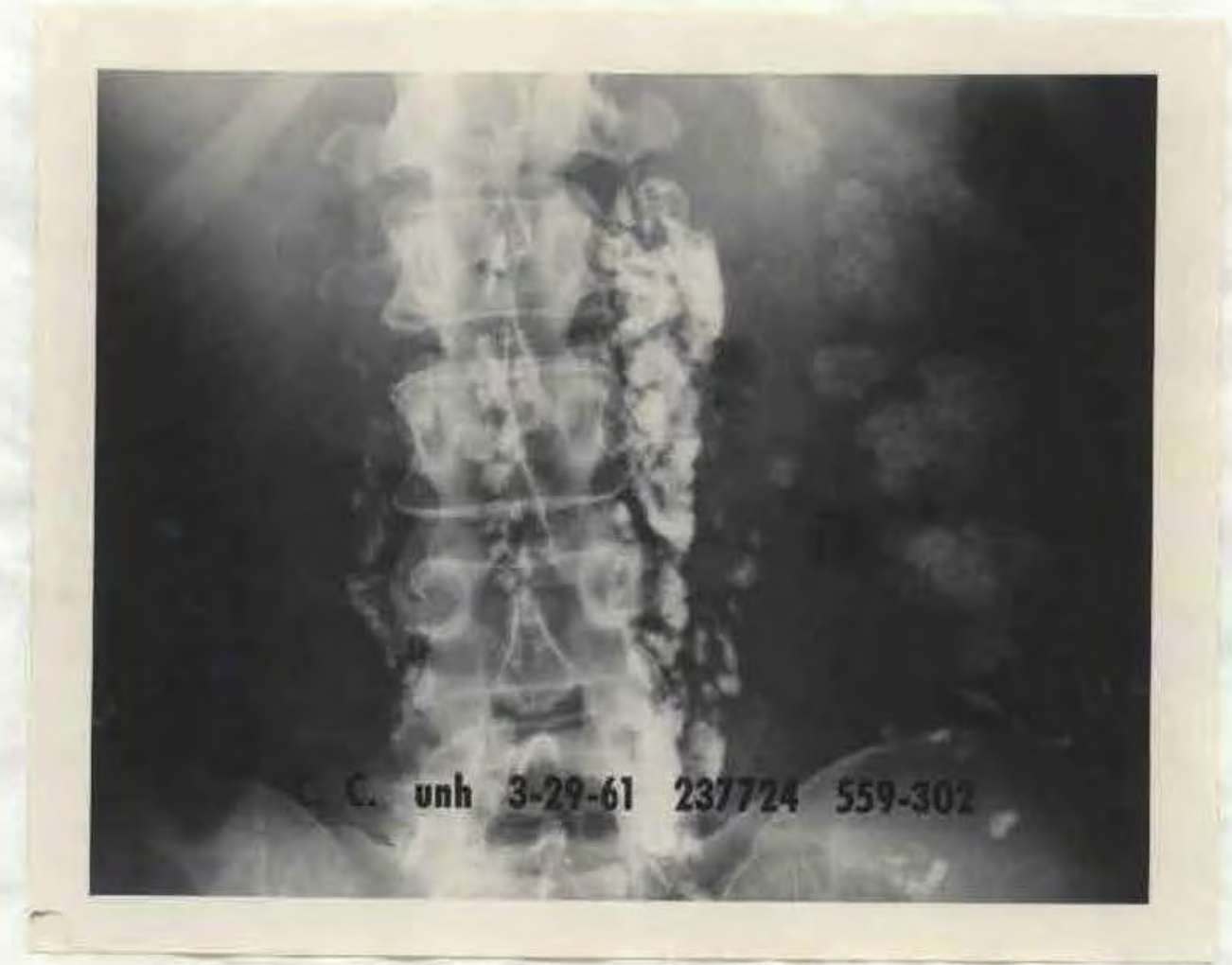

Figure IV - Close-up of enlarged nodes shown in Figure III.

$$
-15
$$


Figure V - Lateral film showing the enlargement and anterior projection of these retroperitoneal nodes.

$$
-16-
$$


LYMPHOGRAMS IN VASCULAR ABNORMALITIES OF THE LOWER EXTREMITIES:

Lymphangiograms of the lower extremities in patients

with post-phlebitic syndrome and other vascular problems

often present unique findings.' The following are lymphangio-

graphic studies attempted in 10 such cases at U.N.H.:

M.G. \# 3-32-18: This 82 year old white female

burned her leg approximately twenty-one years

ago, had subsequent skin grafts, and had an

ulcer on the lower left leg measuring 3 by $4 \mathrm{~cm}$.

on admission. There was a Grade I pitting

edema bilaterally; dorsalis pedis pulses pal-

pable bilaterally. Bilateral lymphograms of

the lower extremities were performed and were considered to be of no diagnostic value, since the water soluble medium was used.

A.J. \#3-32-40: This 72 year old white female had a post-phlebitic syndrome with bilateral varicose veins and granular ulcers on the lower third of both legs anteriorly, medially, and laterally. The ulcer edges were sharp with a small margin of erythema and a proteus species was cultured. A Grade I pitting edema was noted bilaterally; no palpable dorsalis pedis pulses. Bilateral lymphograms revealed an essentially normal picture on the left, but showed a considerable pooling of dye below the skin on the right ankle, suggesting an overlying ulcer, which was present. These films were considered to be of limited diagnostic value, since again the water soluble dye was used.

D.S. \# 1-17-50: This 46 year old white male had a post-phlebitic syndrome with a $2 \mathrm{~cm}$. ulcer on the left lower extremity. He also experienced 
much burning and pain in the extremity, thought to be Iymphangitis. These difficulties had previously been treated by a bilateral lumbar sympathectomy, bilateral greater saphenous vein stripping, skin grafting, and division of the left saphenous nerve for causalgia. A lymphogram of the left lower extremity showed extravasation of dye into the ulcer in somewhat dilated lymphatic channels in the upper leg; inguinal nodes were identified but unremarkable. Again the water soluble media was used and this film was considered to be only moderately good.

C.S. \# 1-16-36: This was a 73 year old white male with edema and cellulitis of the left leg. He had ulcerations on the lateral aspect, probably secondary to chronic venous insuffiency. Several attempts were made to cannulate the lymphatic channel, but these all resulted in failure; therefore, no lymphangogram was available in this case.

E.S. \# 3-79-35: This was a 76 year old white male who had arteriosclerotic vascular disease of the right lower extremity, which led to several gangrenous toes. Medical management failed to lead to a recovery and an above-the-knee amputation was necessary. The stump subsequently developed gas gangrene and on the second post-operative day the the patient expired, in spite of vigorous therapy. Submitted pathologic specimens from the lower extremity revealed markedly narrowed or "pipe-stem" arteries. Lymphograms performed prior to the amputation, again using the water soluble dye, were insufficent to enable any valid interpretations.

I.K. \# 3-49-91: This was a 45 year old white female who had marked varicosities of the lower 
extremities, more marked on the right. There was also a 4 by $4 \mathrm{~cm}$. pigmented area over the right medial maleolus. The gave a history of having developed "milk leg" approximately twenty-one years ago after the birth of her second child. Bilateral venograms showed complete obstruction of the deep veins of the right legs and incompetent perforators of the long saphenous and superficial veins. Lymphograms performed at this time showed good filling of the lymphatics and an essentially normal pattern. However, the radio-opaque medium was injected to vigorously and rupture of lymphatics was seen. Otherwise, the lymphograms were unremarkable. Water soluble dye was used again and was insufficient for adequate interpretation of nodes.

A.I. \#2-12-56: This is a 46 year old white female with severe varicosities of the right leg of post-phlebitic origin. The case was a failure, in that injection of the lymphatics was not accomplished after repeated attempts to cannulate the lymph vessels.

H.B. \# 3-54-05: This was a 75 year old white male who was seen for stasis ulcers of the left leg, duration seven years. There was no history of thrombophlebitis or claudication. Examination of the leg showed brawny induration of the skin and a 1 by $5 \mathrm{~cm}$. ulceration over the left pretibial area, with a granulated base and hyperkeratosis of the margins. Bilateral lymphograms revealed lymphatic continuity from the lower portion of the left leg to the inguinal region. There was suggestion of pooling at the base of the ulcer and several small lymphatic channels were ruptured by the injection. within six hours after the lymphangiograms were performed the patient suffered a heart block, probably secondary to myocardial infarction. No films ise attempted. 
J.M. \# 3-38-09: This was a 69 year old white male who was admitted for swelling in the right leg, penis, and scrotum for six or seven weeks; the episode beginning with pain on the dorsum of the right foot and with swelling. The patient gave a long history of varicose veins. Physical examination revealed no edema of the testes, scrotum, or penis at that time. Lower extremities revealed saphenous varicosities, primarily of the greater saphenous system on the right. The leg was swollen and warm to palpation with brawny edema present up to the right groin area, where there were clinically tender lymph nodes, measuring up to $2 \mathrm{~cm}$. in diameter. In this case Ethiodol was used as the oil soluble medium for contrast. The lymphograms were initially interpreted as being essentially normal, but later review was interpreted as showing smaller and fewer lymph vessels. The thoracic duct was also visualized in this patient. No abnormalities were seen. (See Figure VI.)

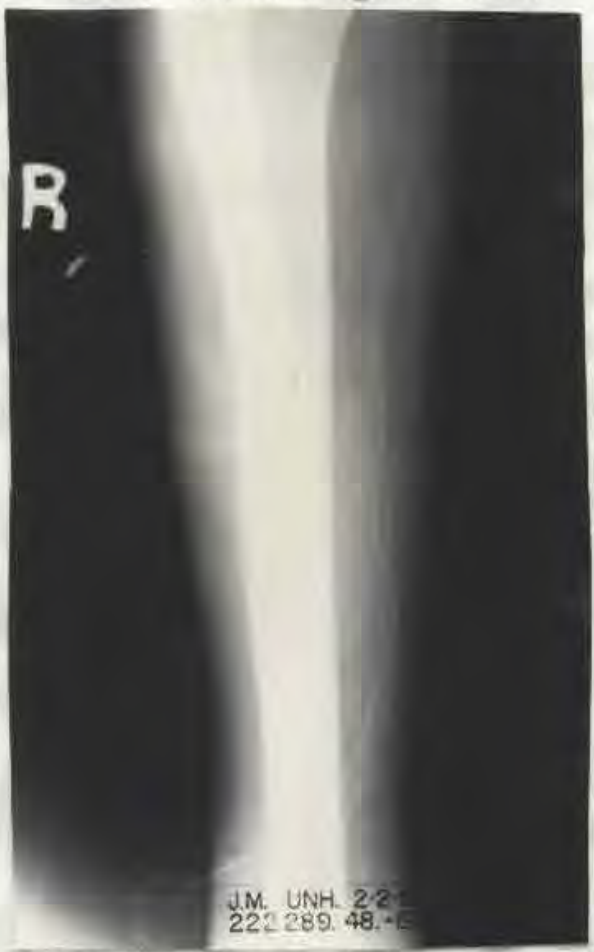

Figure VI. - These Iymphatic vessels were initially interpreted as being normal, but on review interpretation they were considered to be reduced in size and number. 
H.H. \#1-70-62: The patient was a 31 year old white male with a long history of leg trouble, beginning with thrombophlebitis about thirteen years earlier. Ulcers subsequently developed and treatment consisted of right lumbar sympathectomy, excision of the ulcer, and multiple skin grafts of the right lower extremity. The grafts subsequently broke down. When seen, the patient's right lower extremity revealed brawny edema, the leg being approximately three times normal size. There was an ulcer in the pre-tibial area having a purulent and granular base. The pulses were palpable. There was a small, superficial ulcer measuring $1 \mathrm{~cm}$. in diameter on the anterior tibial area of the left lower extremity. Lymphograms demonstrated a pooling of lymph in the base of the superficial ulcer. The lymphatic channels were thought to be smaller and fewer. (See Figure VII) A concomitant osteomyelitis was also demonstrated in the middle third of the tibia of this patient. The ulcer was subsequently excised and a speedy recovery ensued. No followup lymphograms were obtained.

Figure VII - Note the edematous leg, the pooling of dye in at ulcer base, and the relatively few ascending lymphatic channels. 
This series was a relatively fruitless endeavor, since these patients were, for the most part, studied in the "neophyte" stages of lymphangeography at UNH. Of the ten cases, two were failures because of inability to cannulate the lymphatics. Another five films were considered to be of limited diagnostic value due to the use of water soluble medium; this problem of inadequate visualization of lymphatics and nodes was overcome by introduction of the oil soluble medium.

$31,41,43$

Several cases of post-phlebitic syndrome with ulcers and edema gave Iymphographic suggestion of "pooling" of the medium at the bases of the ulcers. This has been described by Blocker et $a l^{6}$ as being a single large channel beneath the ulcer with more vessels appearing up the leg. 23,24 Gergely showed that in post-phlebitic syndrome the lymph vessels are unusually tortuous, irregular and of unequal volume; Kandel, in a similar lymphographic study of thrombophlebitis, felt that the lymph vessels were obliterated. With these findings in mind, it was interesting to note in these UNH patients that, in conjunction with "pooling" of dye beneath the ulcer, the vessels were not dilated but were reduced in size and number. It has been speculated that this "obliteration" of the lymphatic vessels and pooling of lymph may be complicating factors in the course of post-phlebitic syndrome. 34 
LYMPHANGIOGRAPHY IN LYMPHOMATA:

Diseases in the 1ymphomata group are manifest radiographically as showing, in general, nodes of increased size with a "foamy", "lacy", or "ghost-like" appearance."

Some differentiating points between the different types of lymphomatous diseases are:

$7,17,0,58,59,40,3.6$

1. Hodgkin's disease often shows, in addition to the enlarged, "foamy" pattern, central "punched-out" areas in the nodes; Hodgkin's disease has also been characterized by an increased number of smaller nodes, often showing these same rounded filling defects centrally.

2. Chronic Iymphocytic leukemia has the same "foamy" appearance, with area of increased opacity or dye aggregation in the nodes often being seen.

3. Lymphoma has the "foany", "Iacy", or "ghost-like" pattern with nodal enlargement, but may also exhibit irregular filjing defects or architectural alterations.

In advanced stages, none of the preceeding variants in this group can be differentiated by lymphography.

At UNH there were Iymphangiograms performed on a case of each of these three diseases. 
H.M. \# 3-71-11: This was a 65 year old white male who had a massive undifferentiated tumor in the upper lobe of the left lung. Examination of the neck revealed a fullness in the left supra-clavicular fossa with no demonstrable cervical adenopathy. Several small left axillary nodes were palpated. There was marked pitting edema of the left arm. A Silverman needle biopsy was reported as lymphoma, but subsequent tissue diagnoses were those of a highly undifferientiated tumor. Prior to treatment a Iymphogram was performed on the left arm, again using the water soluble medium. The lymphatic channels were visualized rather poorly, as were the axillary nodes. In these nodes the architecture was not discernable due to the use of the water soluble medium. The lymphograws were interpreted as showing no abnormalities; however, venograms subsequently revealed some obstruction phenomena. In this case typical findings of obstruction were demonstrated with venograms. The limited value of this film was demonstrated with venograms. The limited value of this film was attributed to the ineffective qualities of the water soluble medium. The patient was treated at a private hospital with radio therapy and no follow up information was available.

This case failed to give adequate nodal visualization because the water soluble dye was used. This case did serve to emphasize the most important adjunct to lymphography in evaluation of obstruction, venography. 
The following is the only case of Hodgkins disease

on which lymphograms were performed at UNH.

M. E. \# 3-99-34: This was a 47 year old white female seen first complaining of a progressively enlarging mass in the left axilla for four to five years which was nonpainful. Physical examination revealed a well-developed, well-nourished white female in no distress. There were 2 by $3 \mathrm{~cm}$., nodular, non-tender masses in the left supraclavicular region and also numerous $1 \mathrm{~cm}$. shoddy nodes in the left posterior cervical region; no nodes were palpated on the right. The left upper thorax had large multi-nodular, non-tender masses of nodes in the left axilla and in the tail of the breast, measuring about 15 by $20 \mathrm{~cm}$.; the right breast and axilla were unremarkable. The abdomen, extremities, and pelvic examinations were unremarkable. A lymphogram was performed on the left upper extremity and demonstrated enlarged lymph nodes in the epitrochlear, axillary, and supra-clavicular areas. (See Figure VIII) The nodes had a big, "fluffy", "fern-Iike" appearance. During injection there was some rupture of the lymphatic channels due to vigorous injection. Subsequent to the lymphogram a surgical infection developed at the site of incision in the forearm. Bilateral lymphograms of the lower extremities were performed, which showed good visualization of lymphatics in the lower leg within the popliteal region and in the lower pelvis, revealing normal sized nodes in the inguinal region. Films of the pelvis revealed a $3 \mathrm{~cm}$. diameter lymph node in the left iliac region and delayed flow in the right iliac region. It was noted at this time that very poor visualization of the para-aortic and upper iliac nodes occured, since most of the dye was used up in the lower nodes on its assending route. Upon review of the films, a questionable filling defect was noted in one of the left inguinal nodes; these films of the pelvic and retroperitoneal nodes did not show significant involvement.

Surgical biopsy of an epitrocular node gave a tissue diagnosis of malignant lymphoma, most 
likely Hodgkin's disease. This patient then underwent radio-therapy and one month after the first course of Xray therapy the follow-up films showed good visualization of the previously visualized nodes, with an apparent reduction in their size. Unfortunately no follow-up films have been obtained on this patient.

This case of Hodgkin's disease showed involvement of the upper extremity and axilla, but no "punched-out" defects were noted (Etriodol was used). Although the visualization of pelvic and retroperitoneal nodes was not entirely satisfactory, it was felt that no significant involvement, used to follow the nodal response to treatment. 


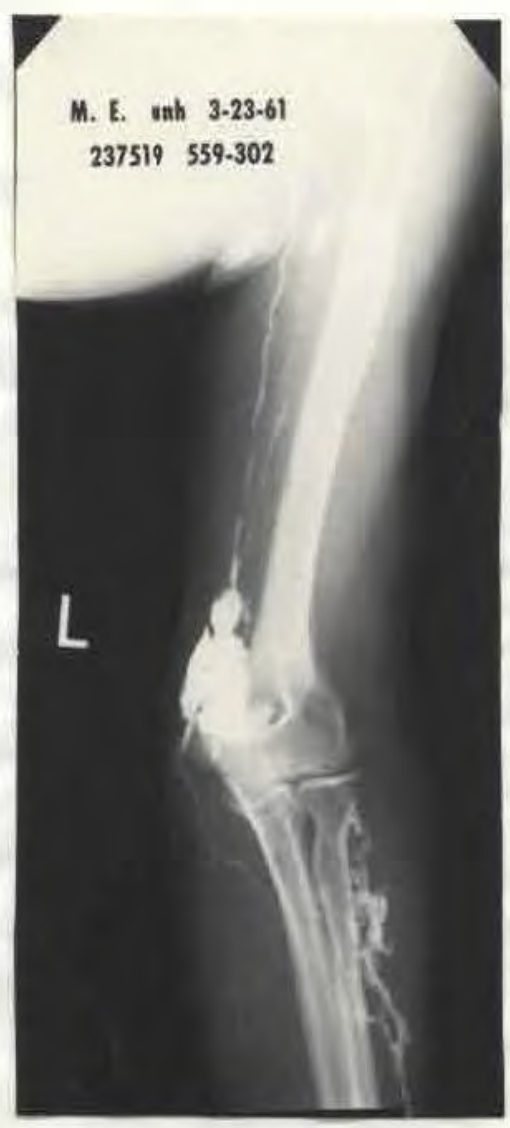

Figure VIII - Iymphangiogram of the

upver extremity showing large epitrochlear

node. The "lacy" pattern is not discernable in the exilla in this photograph. 
Lymphangiography was performed on the following case of chronic Iymphocytic leukemia at UNH.

R.B. \# 3-92-75: This 67 year old white male was seen complaining of enlarging masses in both axillae, neck, submadibular, and inguinal regions of approximately one years duration. Physical examination revealed a well-developed white male in no apparent distress, with no noted ecchymoses. There were numerous, enlarged, firm, moveable, nontender and well outlined masses in the afore mentioned areas, each mass measuring approximately $5 \mathrm{~cm}$. In the axilla, with the cervical nodes varying from 1 to $4 \mathrm{~cm}$. in diameter. Smaller inguinal nodes were present. The initial white count was 36,000 , with the differential showing 3\% segs.; $77 \%$ lymphs; 2 blasts; and 18 prolymphocytes. These findings, in conjunction with the sternal bone marrow aspiration, were consistent with chronic lymphocytic leukemia. The initial lymphograms showed the lymphoma pattern of big, "lacy", "foamy" nodes throughout, with prominent iliac and para-aortic nodes visualized. (See Figures IX and $X$ ) It was felt that the dye precipitated some obstruction to lymphatic drainage from the site of injection. Total nodal occlusion was not demonstrated by "bypassing". The patient was treated with a course of Phosphorous 32 and followup films approximately 8 months later showed much residual dye, with the nodes being approximately the same size as they were before treataent. No followup has been available on this patient other than the eight month films, just discussed as showing no changes.

These nodes showed no areas of increased opacification, although they did have the consistent "lacy" pattern. The 8 month follow-up film showed no response to the $\mathrm{P}_{32}$, possible indicating a change in therapeutic management.

$$
-28-
$$


Figure IX - "Ghost-like appearance of superficial inguinal nodes.

Figure $X$ - Note the marked enlargement of the iliac nodes and the characteristic "lacy" pattern in this case of chronic Iymphocytic leukemia.

B. Bn
P. un 0686

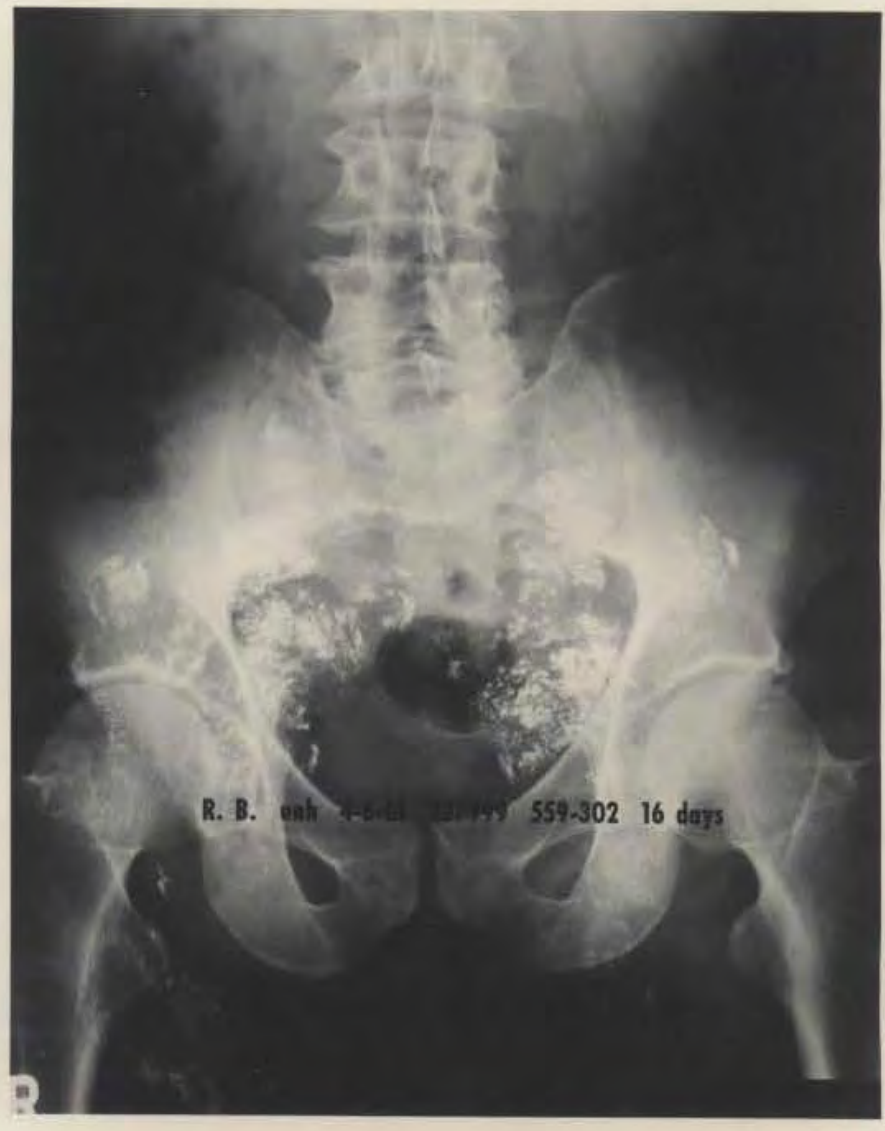


LYMPHANGIOGPAPHY IN THE EVALUATION OF METASTASES:

Formerly, the only method, other than laparotomy, for evaluation of lymphatic spread and retroperitoneal involvement in metastatic carcinoma was intravenous pyelography. It was in itself a rather inexacting study, since its main criteria for evaluation were displacement of or direct involvement of the urinary excretory structures by tumor. With lymphography we are capable of viewing more directly the lymphatic channels and retroperitoneal reticulo-endothelial pathways of metastatic tumor spread. This has been the most popular and controversial aspect of lymphangiography. Criteria used to evaluate lymphatic and lymph node involvement have been stated as follows:

1. Nodes with metastatic tumor may be of normal or increased size.

2. There may be a mareinal "filling defect" in the periphery of the node (not to be confused with the hilum).

3. The node may be completely replaced by tumor and "incirect" signs of involvement may be present, such as displaced lymphatics, collateral lymph channels, Iymphatic stasis with dermal backflow, and/or variations in the calibre of afferent lymph vessels. To complicate the matter, these signs have been 
demonstrated in normal individuals (Ditchek et al did a series of lymphangiograms in prison inmates that showed a high incidence of false positives). Conversely, patients with proven metastatic involvement have had their Iymphangeograms interpreted as normal.

The UNH series of attempted Iymphangiographic

evaluation of metastatic disease follows:

J.S. \#3-94-04: This was a 61 year old white male who was seen for bloody stools and rectal pain for four months, associated with a 20 pound weight loss. Physical examination revealed a thin, well-developed white man who was alert but appeared chronically ill, with signs of recent weight loss. Abdominal examination revealed only a left indirect inguinal hernia. Bowel sounds were active. Rectal examination revealed a circumscribed irregular hard mass palpable approximately 2 to $5 \mathrm{~cm}$. proximal to the sphincter, with considerable blood on it. This mass was apparently well fixed to the sacrum. A metastatic radiographic survey was reported as being within normal limits. Barium enema was reported as showing carcinoma of the rectum without evidence of a second lesion. Bilateral lymphograms were performed and reported at the time as demonstrating the lymph channels and lymph nodes in the lower extremities, pelvic, and para-aortic areas, with suggestion of space filling defects within the lymph nodes of the right inguinal

area.

Upon reviewing these films it was thought that the inguinal nodes certainly did show multiple defects suggestive of neoplasm. (See Figure XII on page 34) However, there was no visible "bypassing". It was noted that the para-aortic chain on the right was relatively void of dye, probable because not enough was injected. (see Figure XI)

An intra-abdominal pelvic perfusion of 5-F'luoraracil 
was performed on this patient and at the time of the operation lymph node specimens were taken from the inguinal and iliac chains. (See Figure XIII) Pathologic diagnosis showed only fibrosis and fatty infiltretion, with no evidence of tumor invasion in these nodes. The primary lesion was adenocarcinoma. At the time of this operation, hepatic metastases were observed and the patient was given a course of cobalt therapy. No further information has been subsequently made available, on this patient concerning his progress. 


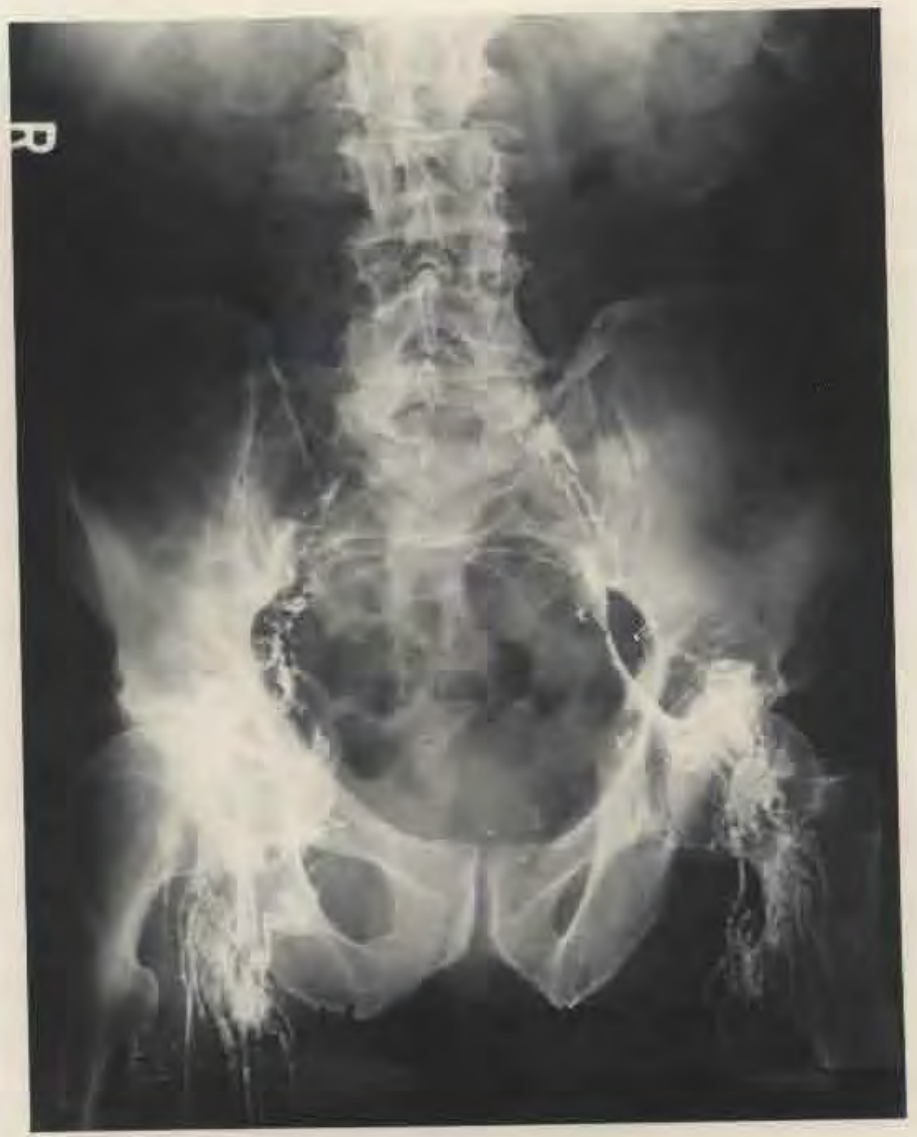

Figure XI - This film was taken immediately after injection and shows a relotive void of dye in the right periaortic chain, possible because an insufficent amount of dye was injected. No interpretation of nodes can be made this soon after injection. The "skip srea" in the left external iliac region is probably due to the oblique angle of the pelvis. 


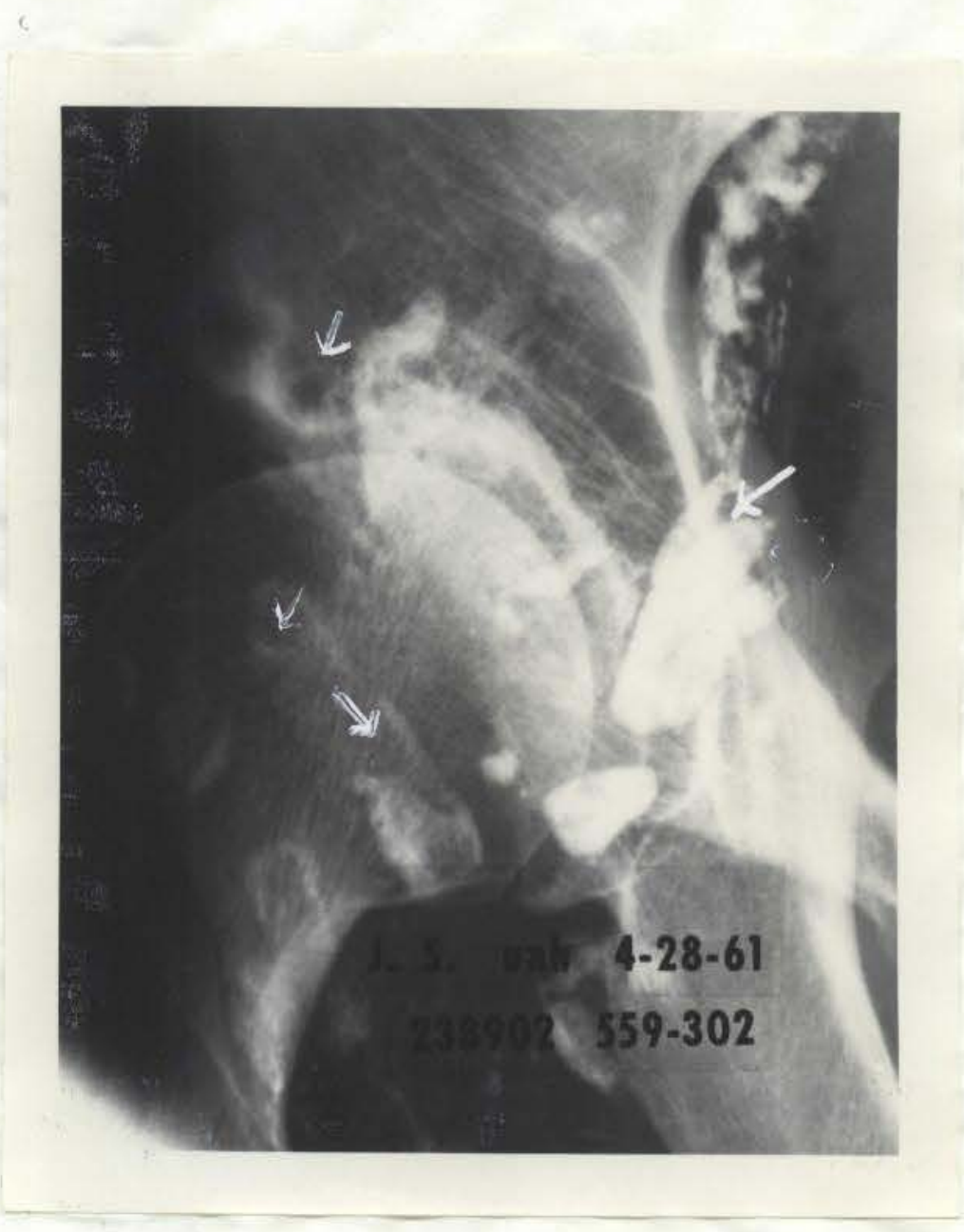

Figure XII - Close up of the nodes in the inguinal region 24 hours after injection. Note the suggested filling defects. 


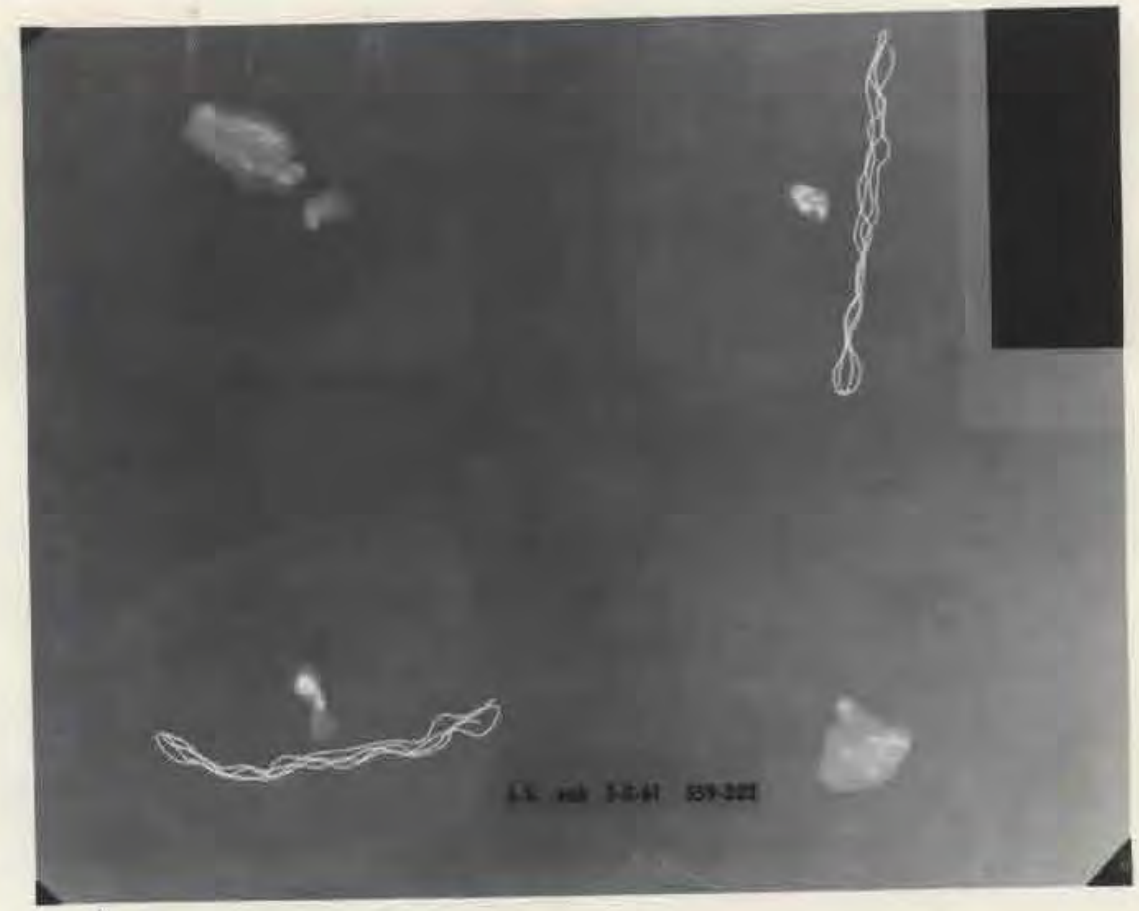

Figure XIII - Radiograph of surgically removed lymph nodes from inguinal region; the nodes were believed to be those showing the previously discussed filling defects. Pathologic study showed only reactive fibrosis in these nodes and no evidence of tumor. However, the patient did have demonstrated metastases elsewhere. 
M.G. \#3-91-02: This 78 year old white woman was seen for an almost complete abdominal obstruction, severe abdominal distention, and pain. She had had intermittent swelling of the right leg and foot for the past four years, and a large mass had been palpable in the lower abdomen for several months. The physical examination was relatively unremarkable for a woman of this age with the exception of the finding of a large, firm, multinodular mass in the mid-pelvis and right lower abdomen. There was no tenderness or guarding. Examination of genitalia was nogative, but rectalvaginal examination showed a mass filling the entire pelvis with cul-de-sac implants. There was also a palpable small moveable mass in the right adnexa higher up and complete fixation on the right; it was difficult to get behind the mass and to find the upper rectum. There were also large bilateral inguinal lymph nodes present. No other signs of lymphadenopathy were demonstrable. A right inguinal node biopsy was performed and grossly this was neoplastic, with microscopic diagnosis being that of papillary adenocarcinoma, most compatable with an ovarian neoplasm. On the same day a lymphogram was attempted on the right leg which was unsuccessful. This failure stemed from the fact that the water soluble medium was used. It is unfortunate that the Ethiodol was not in use at this time since this case would have given excellent opportunity to correlate radiographic and pathological findings.

M.S. \# 3-91-09: This patient was a 30 year old white female complaining of post-coital vaginal bleeding. A D\&C and biopsy revealed an invasive squamous cell carcinoma of the cervix which was initially classified as Stage $I$, with no extention beyond the aterus. The patient was treated first with a radium implant which was followed by a radical hysterectomy and pelvic lymph node dissection. Lymphograms prior to surgery showed several nodes on the left with questionable filling defects. The entire lymphatic chain was well visualized again with the exception of the hypogastric nodes. At the time of operation a 
radical iliac node dissection was attempted;

however, post-operative films showed many

residual nodes which were missed at the time of

the surgery. Pathological report of the specimens submitted showed only fibrosis and fat cell. infiltration. There was no tumor demonstrable. This case was a representation of how lymph node dissection could be aided at the time of surgery by radiographic survey of previously injected radioopaque medium. This patient later succumbed to her illness at home and no post-mortum was performed. 
A.I. 3-93-77: This was a 79 year old wite female hospitalized for a squamous cell carcinoma of the vulva. A 3 by 3 by $I \mathrm{~cm}$. lesion was on the labia monor; there were no significant inguinal nodes palpable on physical examination. Prior to surgery, bilateral lymphangiograms were performed which revealed no abnormalities other than several enlarge inguinal nodes; no filling defects were visualized at this time. When these films were reviewed an interpretation of several questionable filling defects was made, with "scalloping" of the margin of several inguinal nodes.

This patient was treated by a radical vulvectomy and inguinal node dissection (a radiograph was performed on these nodes and showed good dye concentration, although these nodes could not be accurately matched with nodes seen on the original lymphangiograms). Fost-operative $X$-rays of the inguinal region showed the extent of the node dissection. (See Figure XIV)

The pathologic specimens from the operating table consisted of a left vulva which contained invasive squamous cell carcinoma, and about twenty lymph nodes from the right and left inguinal regions, none of which showed any evidence of tumor invasion. These nodes showed only scarring and reticulum hyperplasia, with many foreign body giant cells.

The patient succumbed later to apparent metastases in her hone and no autopsy report was available. 
Figure XIV -

Note the absence of

nodes in the ingui-

nal region following

surgical dissection.

None of the speci-

mens showed evidence

of tumor. It is eve-

dent here the surgeon

performed an adequate

inguinal node dissec-

tion, but failed to

remove the node

conteining a filling

defect in the iliac

chain.
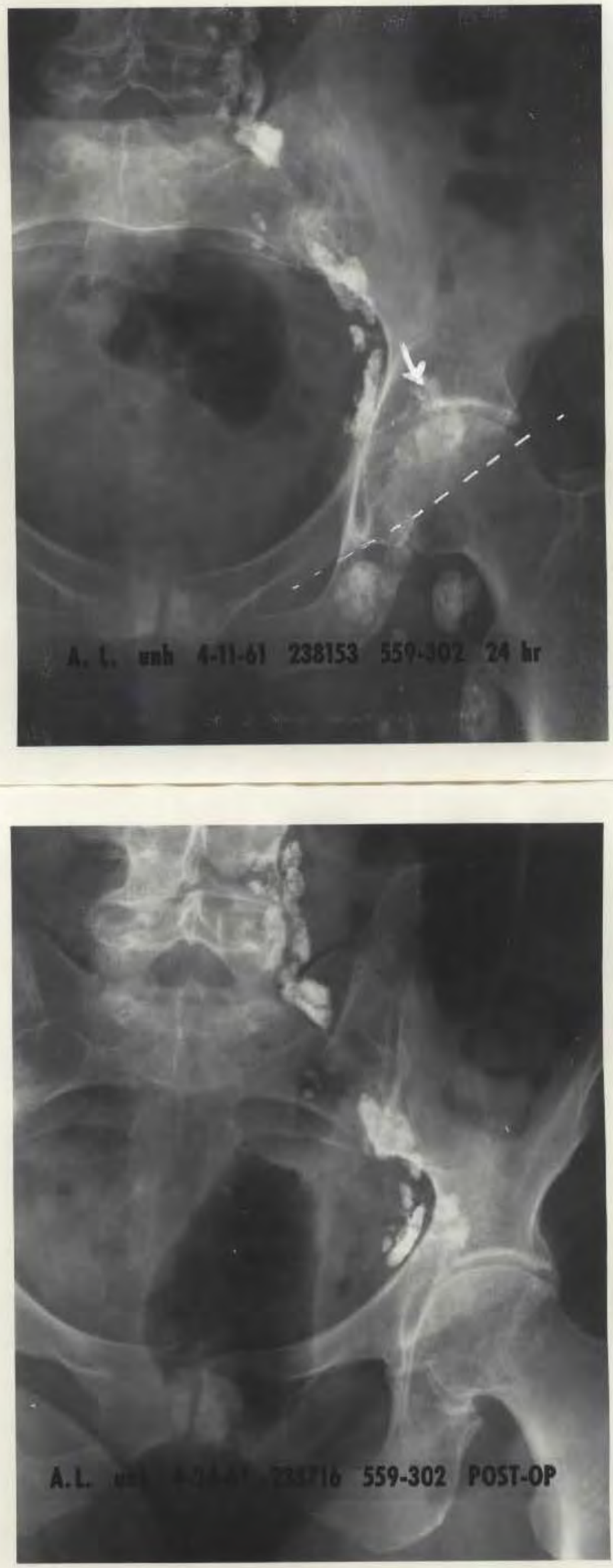
N.L. \# 3-72-92: This was a 46 year old white female admitted with a history of having a squamous cell carcinoma of the cervix which had been treeted elseWhere by a total hysterectomy and irradiation. On a subsequent UNH admission a laparotomy was performed with the possibility of performing a pelvic exeneration in mind, but when the surgeons discovered marked extention of the tumor to the para-aortic nodes they decided not to do the radical surgery and treat the patient with further irradiation. Biopsy of a left iliac lymph node revealed metastatic sauamous cell carcinoma. No lymphangiograms were performed on this admission.

On the final admission the patient had small bowel obstruction. Lymphangiograms were performed at that time and were interpreted as showing filling defects in peri-aortic nodes with no defects visualized in either of the areas previously interpreted as being involved with tumor. It was noted that films taken three days after the initial Iymphangiograms still showed a marked amount of dye remaining in the lymphatic channels; this delayed emptying time was felt to indicate extensive nodal involvement with tumor which caused a blocking of lymphatic flow.

Celiotomy revealed multiple perineal and iliac tumor implants. Specimens taken at this time included a common iliac lymph node, which microscopically showed considerable fibrosis and fatty replaccment, with a small collection of moderately plecrmorphic tumor cells at the periphery, diagnosed as squamous cel] carcinoma. Another lymph node, taken at the aortic bifurcation, microscopically showed only fatty and fibrous tissue with an absence of lymphoid elements. Other lymph nodes taken from omentum and small bowel showed squamous cell carcinoma. Silver clips were placed to identify the nodes removed, thus enabling post-operative radiographic correlation. (Bee Figure XV) The nodes removed from the site of the clips were either non-visualized or unremarkacle on the initial radiograph interpretation.

This patient subsequently succumbed to metastatic carcinoma of the cervix. Autopsy sections revealed widespread iliac and peri-aortic nodal involvement. 

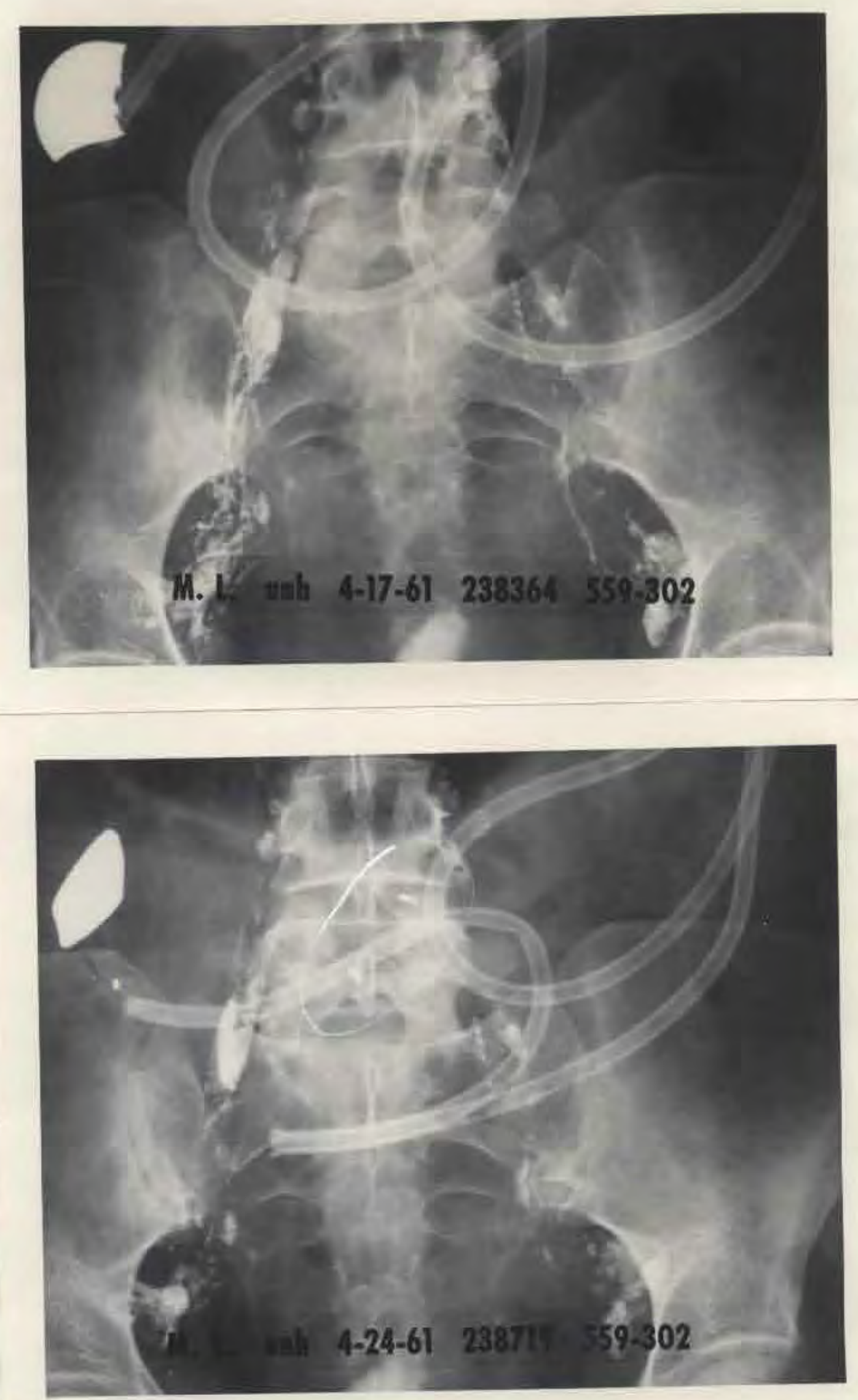

Figure XV - Pre- and post-operative films, showing, by means of silver clips, the nodes which were removed. The lower note was not visualized. The upper was not considered remarkable. Pathologic examination showed only fibrosis and fat in these nodes. 
B.C. \# 3-90-49: This was a 49 year old white female admitted for stage III squamous cell carcinoma of the cervix. This lesion was treated with radiation and radium implants. Lymphograms of the lower extremities were performed on this patient and it was noted that the lymph channel on the left circumvented the inguinal nodes and passed directly into the external iliac nodes. There was a suggestion that the lymphatic channels along the external iliacs on the right were somewhat compressed and distorted, with those on the left appearing normal. (See Figure XVI) The nodes were interpreted as being of normal size with no evidence of filling defects. The thoracic duct was demonstrated. Films taken two weeks later showed persistence of dye in the pelvic and aortic lymph nodes. Films taken approximately one month after this still showed the dye to be well concentrated in the pelvic and aortic lymph nodes, with essentially no change in node size. Venograms taken at this time revealed questionable distortion and pressure defect of the right external iliac nodes. A review of these films was interpreted as showing proximal obstruction to the flow of lymph illustrating reflex and smaller vessel filling. (See Figure XVII) About two years following the initial lymphogram, a celiotomy (performed because of bowel obatruction) was necessitated and wide spread metastases were observed in liver and omentum, although no specimens of lymph nodes were taken from the iliac or para-aortic areas. At this time there was no mention made of residual dye. The patient was dismissed from the hospital and later expired at home. No autopsy was obtained. 


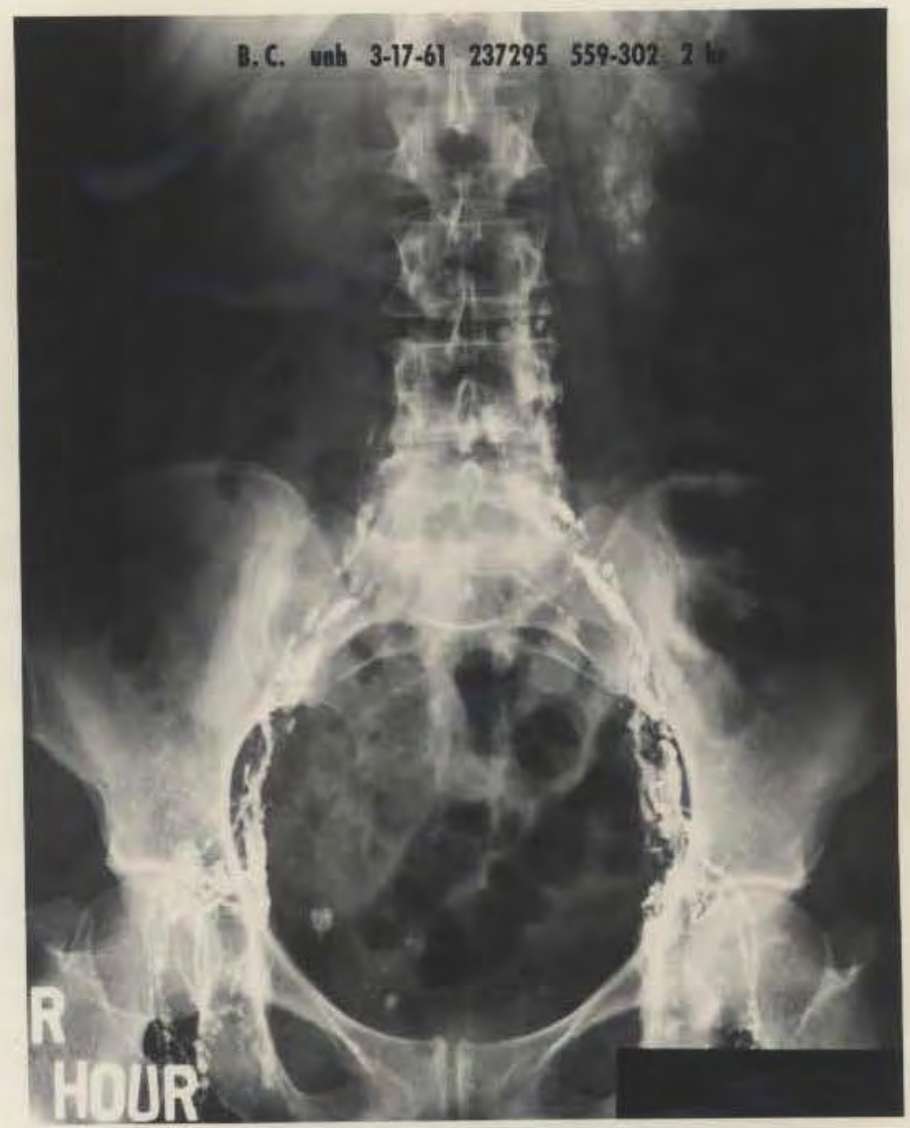

Figure XVI - This one hour film shows questionable compression and distortion of the right external iliac chain. 
B.C. whi $3-17-61 \quad 237295 \quad 559-302 \quad 45$ mil

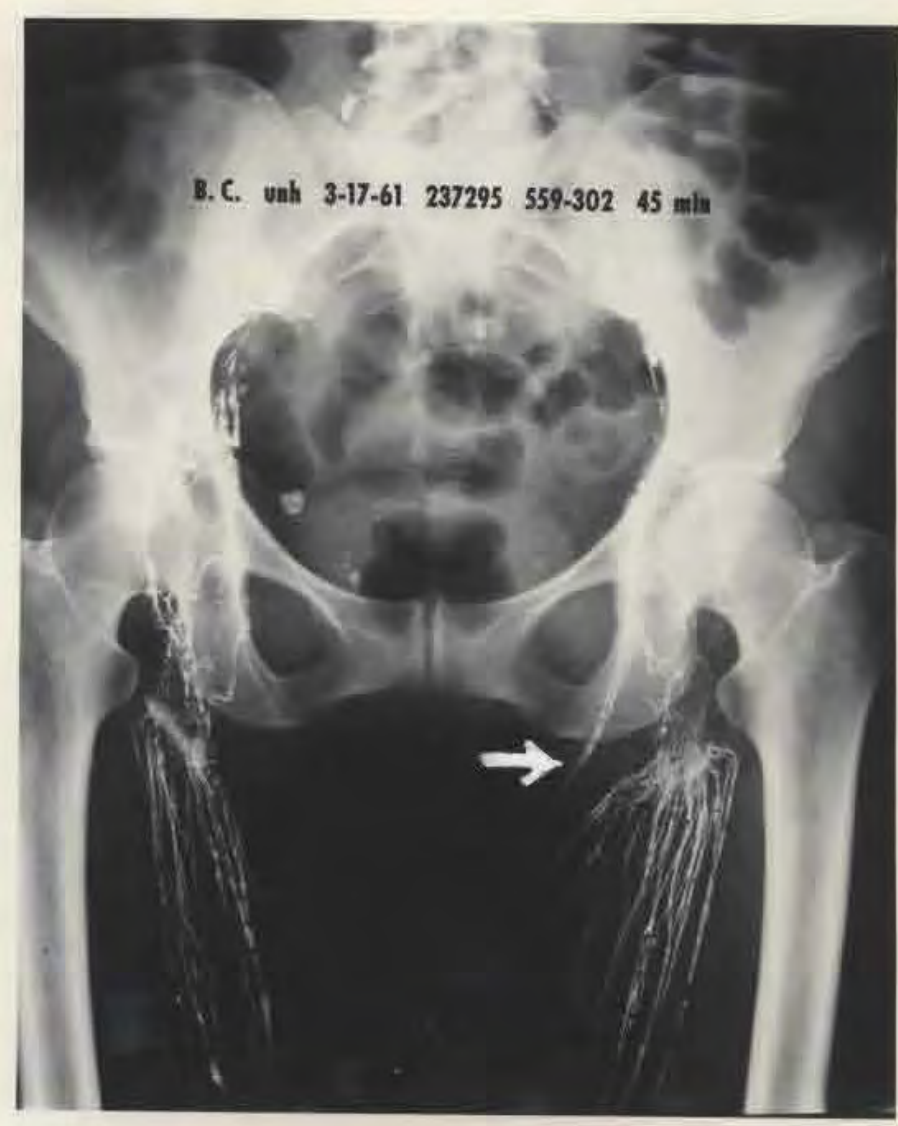

Figure XVII - Note the dermal backflow and small vessel filling, often a criterion of proximal obstructive phenomena.

$$
-44-
$$


S.B. \# 2-94-57: This was a 66 year old white female seen with an enlarging mass on the right thigh of approximately one years duration. She also had a mass in the right groin. Physical examination was essentially negative, except for a 4 by 4 by $3 \mathrm{~cm}$. mass, which was raised, bluish, and non-tender, involving the right anterior and lateral thigh with firm subcutaneous extension for approximately $67 \mathrm{~cm}$. in diameter. There were three gangrenous areas on the surface of the mass from previous biopsies, which were reported as showing malignancy. There was also a 6 by $8 \mathrm{~cm}$. hard, non-tender mas in the right inguinal region which was felt to be matted nodes; no peripheral edema was noted. Bilateral lymphograms were performed and the channels on the left were essentially normal appearing with subsequent filling of the iliac and para-aortic nodes. The right side, however, showed a rather baziarre pattern of lymphatic filling with apparent obstruction in the region of the right iliac node; there was reflux of dye retrograde into the right vulva. Dye was visualized within the right iliac nodes, these appearing to be slightly fluffy and lacy. There was a relative void in the lymph node pattern in the right inguinal region. This primary tumor was treated by surgical excision and irradiation, since it was thought to histiologically resemble a reticulum cell sarcoma. One specimen taken by needle biopsy of a right inguinal node showed malignancy also. No follow-up has been done on this patient in the last two years.

M.s. \# 4-05-00: This was a 36 year old white female seen for a stage III carcinoma of the cervix. Clinically there were palpable inguinal nodes, femoral nodes, several axillary nodes, and a large node in the left supra-clavicular fossa; Hepatomegaly was also reported. Bilateral lymphograms via the lower extremities revealed nodes on the right side that were interpreted as essentially normal. The left lymphatic channels appeared normal; however, nodes along the internal iliac, at a level just distal to the crossing of the 
external iliac over the ilio-pectineal line, appeared to be slightly enlarged with possibly some destruction and development of collateral channels. Common iliac and para-aortic nodes appeared normal. A later review of the films was essentially that as stated except it was felt that filling defects were marginally seen on left inguinal and para-aortic nodes. This patient was treated by a posterior pelvic exeneration, with a bilateral pelvic lymph node dissection. The pathologic specimens were meticulously examined and revealed an invasive squamous cell carcinoma of the cervix with metastases to the uterus and extention to the vagina. However, of the thirty-one lymoh nodes examined, including right and left external iliac, para-aortic, left obturator, left common iliac, appendiceal, and right and left hypogastric nodes, none of the thirty-one specimens were observed to contain any evidence of tumor involvement. These nodes were observed, however, to have their architecture extensively replaced by vacuoles and many multi-nucleated giant cells; they also showed marked reticulum cell hyperplasia. No radiographic follow-up has been done on this patient in the way of lymphography, but she is apparently doing well to the present date.

E.P. 5-18-60: This is a 52 year old white female seen with the diagnosis of carcinoma of the cervix, post-irradiation status. When seen there was no evidence of tumor on pelvic examination and there were no masses in the inguinal region. This carcinoma was previously staged at II. Metastatic survey was negative. Bilateral lymphograms performed prior to a totel hysterectomy and pelvic node dissection were considered to be completely within normal limits on first interpretation. Three days following the radical procedure, approximately $70 \%$ of the dye was seen to disappear, and the approximate node removal areas were visualized. A review of the preoperative lymphograms was interpreted as showing multiple defects on the right and left inguinal 
nodes. Ihe pathologic diagnosis of the uterus and cervix was that of mild cervical dysplasia. Multiple node specimens showed some calcification, with fat cells and no germinal action. lhere was no evidence of malignancy seen in any of the noles. bpecinens included right and left comion iliacs, ripht and left hypogastrics, and right and left obturator nodes. A left supraclavicular node was also visualized on the follow-up film at twenty-four hours. This patient is now beinf actively followed in GYN Clinics and is doing well.

L.B. $75-2<-94$ : This is a 39 year old white female seen with a Stage III squamous cell carcinoma of the uterus and cervix. No nodes were palpable. Bilateral lymphograms of the lower extremity were attemoted with failure on the left side, but adeauate iniection on the right. No abnormalities were noted on the pelvic and abdominal films, and adecuate visualization was made of the right femoral, external iliac, common iliac, and para-aortic nodes. At twerty-four hours a large left supraclavicular node was noted.

A radical hysterectomy was carried out on this patient with node dissection. Post-operative filas showe an int rval surgical romoval of some of the lymphatic chain along the external iliac and common jliac artery on the right side. A review of the films revealed two nodes which were suggestive of containing filling defects, and which remained behind in the right pelvis following this surgical procedure. A pathology report showed that aII nodes submitted showed a loss of germinal centers with some histiocytic proferation, marked fatty infiltration, and predominant fibrosis. No malignancy was seen in any of the nodes submitted, which included the right and left obturators, common 
iliacs, external iliacs, and hypogastric nodes. No further information is available on this patient since her dismissal from the hospjtal.

L.G. \# 5-38-04: This was a 34 year old white female who was seen at the University Hospital because of a vesiculo-vaginal fistula, which was secondary to a total abdominal hysterectomy previously performed on her in another hospital. The diagnosis from the other hospital was that of an invasive squamous cell carcinoma of the uterus and cervix. Bilateral lymphograms of the lower extremities were interpreted as showing no definite abnormalities of the lymphatic drainage of the left leg and pelvis. On the right, few lymphatic channels were seen in the lower leg and upper portion of the right leg with very little filling of the nodes demonstrated. A twenty-four hour film showed a few scattered lymph nodes on the right to be filled and there were several large "skip areas" along the lateral margins of the pelvis. This was interpreted at this time as probably representing nodal involvement secondary to neoplasm, or nodal fibrosis, or surgical induced absence. An abdominal operation was performed for removal of the upper third of the remaining vagina, for lysis of massive intestinal adhesions, closure of the vesiculo-vaginal fistula and bilateral pelvic lymphadenectomy. Surgical pathology specimens consisted of several right common iliac nodes measuring 4 by $11 / 2$ by $1 \mathrm{~cm}$. These nodes showed some degenerative changes and fatty infiltration. There was also some histiocytic proliferation and many foreign body type giant cells noted; there was a good deal of fibrosis, but no evidence of tumor. A second specimen consisted of four Iymph nodes from the right obturator region measuring 7 by $2 \mathrm{~cm}$. These nodes showed a similar histologic pattern of the right common iliac nodes, however, two of these nodes were partially replaced by malignant neoplastic cells. Other submitted specimens consisted of nodes from the right pararectal area area and the left external iliac nodes. These nodes showed the histologic pattern previously 
described, with the exception of the fact that there was no neoplasm identifiable in any of these other specimens. Post-operative films of the pelvis showed segments of nodes to be missing in both the left and right iliac regions, with no other remarkable features observed. In this case it was felt that the right obturator nodes, which were felt to possibly contain malignant activity prior to surfery, were the ones removed at the time of surgery which did show neoplasm. This patient was treated with irradiation and chemotheragy and no follow-up is available.

M.F. \# 2-90-81: This was a 62 year old white female who was seen with post-operative complaints following a left colectomy for adenocarcinoma of the sigmoid colon two years prior to this addmission. Approximately eight years prior to that, she had had a carcinoma of the cervix, which was treated at that time with radiation and had supposedly remained asymptomatic. Physical examination revealed an elderly, extremely thin, alert white female, who appeared chronically ill. She had a nephrostomy tube passed through the right side, which had been necessitated by a pyelonephritis resulting from ureteral obstruction, secondary to carcinoma.

Lymphograms of the lower extremities visuelized the inguinal and para-aortic chain. It was felt that an insufficient amount was injected into the lymphatics on the left side. The inguinal nodes showed no abnormalities, and the external iliac chain appeared normal. The para-aortic chain appeared normal on the right to the level of L-2, at which level there appeared an enlargement of a node measuring about $3 \mathrm{~cm}$. In width and about $41 / 2 \mathrm{~cm}$. in length, with persistent radio-lucent defects suggestive of metastatic disease within the node. On reviewing the films at a later time there were "skip areas" seen in the right iliac group and several questionable fillino defects in the inguinal nodes on both sides. The defect in the area of $\mathrm{L}-2$ to $\mathrm{L}-3$ which was thought 
to be tumor, was also questionable interpreted as possibly representing adenitis secondary to the nephrostomy tuoe. (See Figures XVIII and XIX) The patient ran a rapid downhill course and expired. Autopsy correlation with the lymphograms showed that what was thought to be a tumor at $\mathrm{L}-2$ to L-3 was not a tumor at all, but a large lymph node whose hilum was replaced with fat and fibrosis. There was, however, a node inferior to this suggested defect which was completely missed on the lymphogram. This node was replaced almost entirely by tumor. A node in the external iliac chain which had a questionable filling defect was shown to contain no tumor but only a fatty infiltrate and fibrosis. There were several smaller lymph nodes in the common iliac chain on the right side which were interpreted as being unremarkable on the lymphogram but showed almost complete replacement with tumor and necrosis. The tumor was of the adeno-carcinoma variety. 


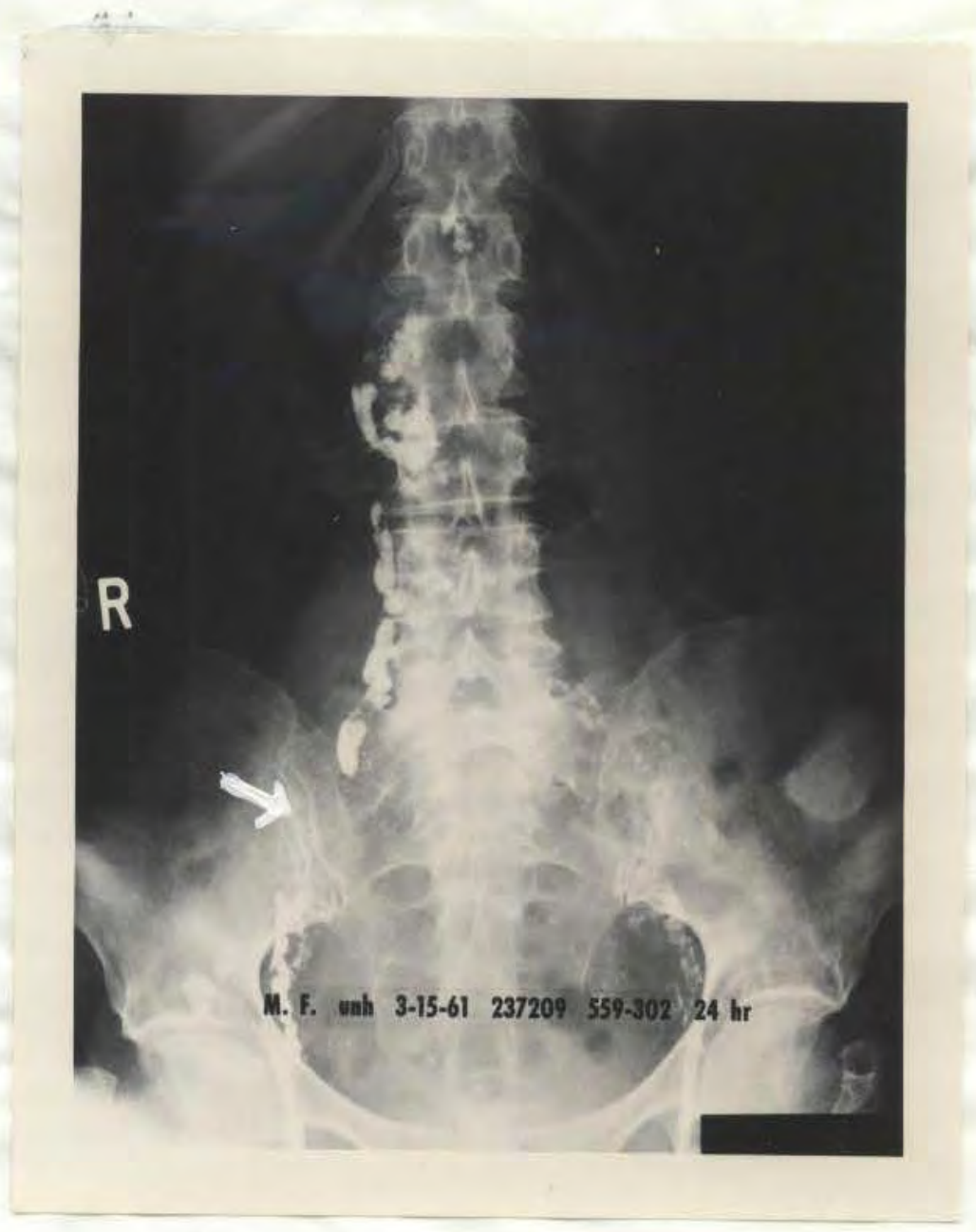

Figure XVIII - Note poor visualization of left iliac and peri-aortic lymphatics, believed to be secondary to insufficient amounts of dye injection The large" skip area" on the right was found at autopsy to contain much tumor. 


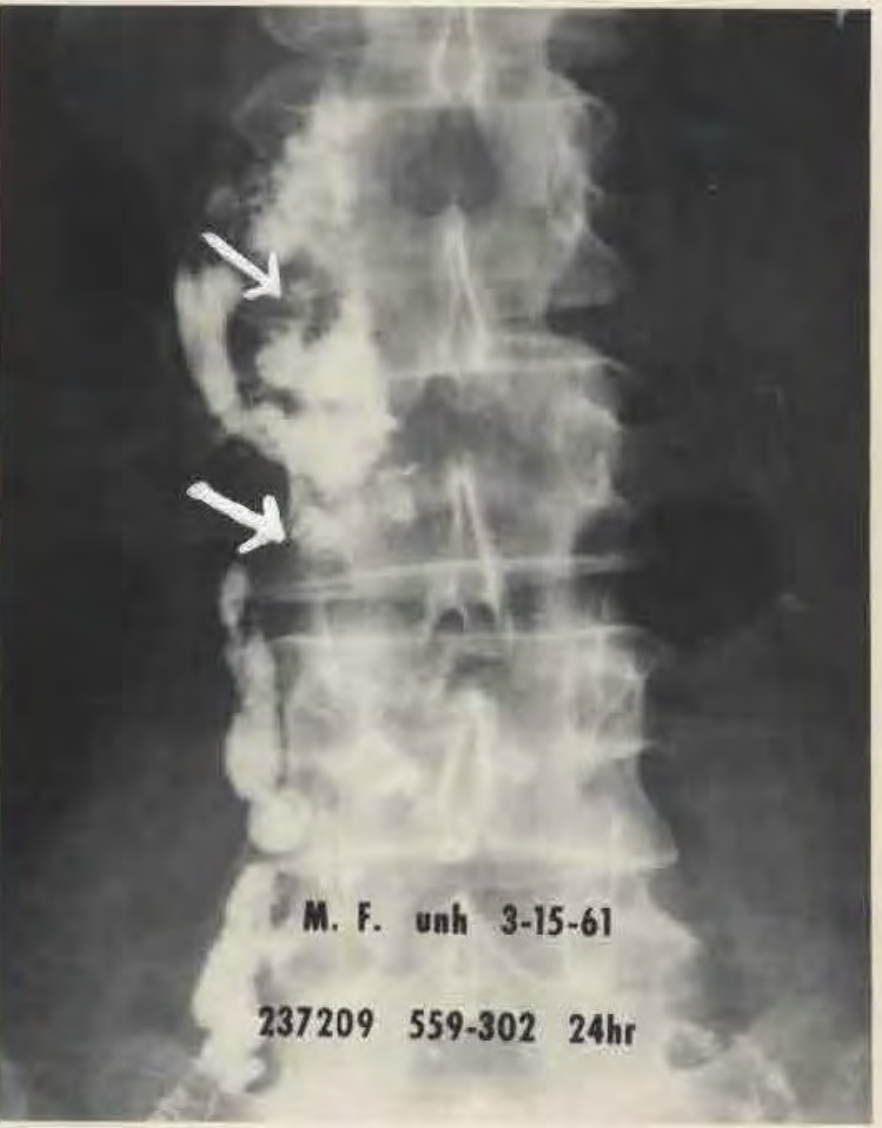

Figure XIX - Close-up of Figure XVIII showing enlarged node at I-2, felt to have filling defects. This node was a result of inflammatory changes and contained no tumor. The void area shown below this node did, however, contain metastatic adenocarcinoma. 
In this limited series, one film was inadequate due to the use of water soluble medium. There were 6 false positives, in other words, filling defects were visualized, but no tumor was demonstrated. There were 4 cases interpreted as showing signs of tumor which yielded positive nodes for carcinoma, although there was not perfect correlation between the node visualized as abnormal and the node examined histologically. There was one case in which the lymphogram was interpreted as being within normal limits and the patient had positive nodes (false negative). Correlation of all of these cases has been extremely difficult in that many patients returned to their homes and succumbed, with no post mortem findings being made available from their local physicians. Schaffer et al state that the diagnostic value of lymphangiography in metastatic disease is often unreliable because of several factors:

1. It requires relatively lare metastatic deposits in lymph nodes to create defects radiographically detectable. Many small metastatic lesions probably go undetected. The smallest lesion he detected and correlated was $4 \mathrm{mr}$. in diameter.

2. Nodes completely replaced by tumor will not be visualized and there may be no signs of obstruction and backflow or of collaterals. 


\author{
15 \\ 3. Nonmalignant defects (ie., fat and fibrosis) frequently \\ occur in nodal parenchyma, especially in the inguinal \\ and pelvic nodes, which may simulate metastatic cancer \\ on the lymphangiogram. A prominent hilum may also be \\ confusing. \\ 4. Certain lymph node groups involved in tumor spread \\ from some central lower pelvic organs are not visualized \\ by present techniques. The external iliac chain is \\ visualized but the hypogastric nodes are not available \\ to study by peripheral lymphangiography.
}


OTHER USES AND INDICATIONS:

In addition to the previously discussed uses of lymphangiography in the evaluation of inflammatory disease, post-phlebitic syndrome, lymphomata, and metastic carcinoma, several other diagnostic and adjunctive aspects of lymphangiography are of importance. $36,44,51,54$

1. The evaluation of lymphedema may be greatly aided by Iympangiography as to the sight of either obstruction or congenital anomaly which may be a causative etiology of lymph stasis or backflow. Arteriography and venography should be performed first to give better diagnostic results. Correll and Fischer ${ }^{2}$ reported visualization of a congenital lymphangioma of the thoracic duct, causing lymphedema.

2. Chylothorax or chyloperitoneum due to surgical laceration of the thoracic duct may be aided in treatment by location of the trauma with Iymphangiography.

3. Lymphangiography may be valuable adjunct to the surgical location and removal of nodes.' Radiographs may be performed during surgery to show nodes which have been missed and which may still be amenable to dissection. A recent improvement has been the addition of a chlorophyll dye to stain the nodes and aid direct visualization by the surgeon.

$$
-55^{-}
$$


4. Lymphangiography has proven to be of value in guiding the radiologic therapist in placing his irradiation portals. so, 58

5. The effects of irradiation therapy and chemotherapy ${ }^{28}$ on the Iymphatics often can be followed by Iymphangiography and thus aid the therapist in his evaluation of these agents on the disease being treated.

6. Intralymphatic chemotherapy has been attempted but, as previously mentioned, has yielded poor results.

7. Several investigators have reported certain abnormalities of a non-specific nature in the abdominal thoracic duct in patients with carcinoma of the pancreas. It is possible this could become an aid to diagnosis of pancreatic carcinoma, although the probability is remote.

8. A study ${ }^{35}$ has been reported in which the circulating blood has been searched for tumor cells when the patient is undergoing lymphangiography. This was shown to actually occur in one patient. The mode of entry of tumor cells into the blood stream was hypothesized as either occuring via the thoracic duct or else by nodal compression from the injection of the intralymphactic medium, thus forcing tumor cells into adjacent or invading blood vessels.

$$
-56
$$


COMPLICATIONS:

As with any surgical procedure, Iymphangiography has its complications. Most of these are not life-threatening to the patient, but nonetheless there are inherent dangers. I. The site of surgical incision in the dorsum of the foot may become infected, probably due to the fact that the wound is exposed to air contamination for relatively long periods.

2. Some adverse cosmetic effects may occur due to the injection of too much dye used in outlining the lymphatics. A discoloration of the patients skin has also been reported following use of the chlorophyll dye in the radio-opaque medium.

3. Overzealous injection of the radio opaque medium often causes rupture of lymphatic channels. This may cause pain and possibly lymphedema in the extremity injected.

4. Pain is sometimes experienced when the dye reaches the inguinal nodes in some patients -- this is thought to result from distention of the lymphatics.

5. Fever is a transient symptom which sometimes occurs and is treated symptomatically.

6. Hausea and vomiting have been reported as occuring during the injection of the dye. No physiologic basis is known 
for this and it is probably a manifestation of the patients anxiety.

7. Intravenous injection of the dye could present a major hazard to the patient, since a massive oil embolization in the lungs could occur.

8. Oil embolization does in fact occur, in up to $55 \%$ of the patients, according to a study by Bron et al. This embolization is most often manifest by the presence of diffuse stippled densities seen throughout both lung fields. Very few patients actually have symptoms, however. This is felt to occur through lymphatico-venous communications, and is more likely to occur with some proximal obstruction to lymph flow.

9. Lymphangitis may prove to be a chronic and troubleaome complication following lymphangiography.

10. Swollen extremities have been reported and the etiology of this is most likely lymphatic obstruction leading to a lynphedema; this condition almost always corrects itself in time. The question of lymphangiography causing obstruction has often been raised and it has been shown by repeat Iymphangiograms that the incidence of obstruction caused by the initial study is very low.

11. It should be kept in mind that if there is any necessity of the patient undergoing thyroid function studies, these 
tests should be performed prior to lymphangiography. The PBI and I 131 uptake are grossly deranged following lymphography, often for a long time.

\section{HISTOPATHOLOGY:}

Following lymphangiography there appears to be certain characteristic changes seen in various tissues; these changes have been studied by schaffer et al, and their findings have been concurred with by many.'

1. Lymph Nodes: Small amounts of radiographic medium have been demonstrated in lymph nodes up to 24 months following Iymphangiography. The medium is located in the sinusoids in the form of small globules; these may coalesce, rupture the walls of the sinusoids, and form pseudocysts. Foreign body giant cells are usually plentiful and there is no evidence of neutro philic infiltrations. There is apparently no drainage to the nodes or increased incidence of fibrosis. It has been shown that only normal lymphatic tissue is opacified and filling defects may be visualized from tumor implants or from fatty infiltration or from fibrosis, most likely the result of chronic infection distal to the node.

2. Lungs: The Ethoidol has been reported as being present initially within the alveolar spaces following lympho-

$$
-59-
$$


graphy. In autopsy specimens no Ethoidol was demonstrated in the lungs several months after injection.

3. Kidneys: Ethoidol has been visualized in the glomerular and peri-tubular capillaries in some $20 \%$ of autopsies. When it was present in the glomerular capillaries, no blood cells were visualized in the corresponding Bowmans space. There were no evidences of ricroinfarction or inflammatory changes.

4. Examination of other tissues has been unremarkable and these studies have indicated that major portions of Ethoidol remain in the lymph nodes. Some passes from lymphatics to venous circulation and then into the lungs, where most of it is removed. There are, however, small amounts which enter into the arterial circulation, and apparently no untoward histologic effects have been noted. 


\section{SUMMARY:}

An introduction to lymphangiography has been made, including a brief historical review. Technique and materials used in lymphangiography were discussed. Radiographic findings considered to be within normal range were presented.

The use of Iymphangiography at the University of Nebraska Hospital has been studied and a review made of all patients having lymphangiograms from 1960 to 1963. Wherever possible the radiographic findings were correlated with pathologic findings in order to evaluate the reliability of the procedure. The diagnostic criteria used at WNH has been extropolated from a literature review of the topic and the salient features from the literature have been presented.

Various other uses of lymphangiography, beyond those employed at LNH, have been mentioned. 


\section{CONCLUSIONS:}

Due to the fact that lymphangiography has been used to a limited extent at UNH, the series of cases studied has not been large enough to substantiate many positive conclusions. Radiographic correlation with pathologic findings has been very difficult because many post-mortem reports have not been made, and in several cases in which there was tissue diagnosis, no mention was made of the exact location, in vivo, of the specimen so that correlation could be made possible.

The use of lymphangiography in post-phlebitic syndrome and inflammatory disease provides radiographs which lend little to the diagnosis or treatment of the patient. The most reliable diagnostic use of lymphangiography appears to be in the lymphomata diseases, and poor diagnostic reliability exists in the evaluation of metastatic disease. One of the more important contributions of lymphangiography promises to be its aid to the dissection of Iymph nodes. Another useful adjunct is portal placement for irradiation and the follow-up of nodal responses to therapy. It would appear that following establishment of better technique and familiarization with radiographic interpretation, a much greater success could be enjoyed than now prevails. 


\section{ACKNOWLEDGEMENTS}

I would like to express my appreciation to Dr. William Karrer, Department of Surgery, and Dr. Nathan Adkins, Department of Radiology, for their time and assistance. 


\section{BIBLIOGRAPHY}

1. Altman, D. and others; Am. J. Dis. Child. 104:335, 1962, (cited by) Modern Medicine (Jan.) 1963.

2. Arnulf, G.: Practical valve of lymphangiograph of the extremities. Angiology 9:1, 1958.

3. Arnulf G.: The value of lymphography., Minerva Chir 16:717 (June) 1961.

4. Averette, H.E. and others: Lymphangio-adenography as a guide to lymphadenectomy. Obstet. Gynec. $21: 682$ (June) 1963 .

5. Bennett, H.S. and Shivas, A.A.: The visualization of Lymph nodes and vessels by ithyl lodostearate (Angiopac) and its Effect on Lymphoid tissue. J. Fac. Radiologists 5:261 (April) 1954.

6. Blocker and others: studies of Ulceration and Edema of the Lower Extremities by Iymphatic Cannulation, Ann. Surg. 149:884-89? 1959.

7. Bower, R. and others: Radiographic studies of the Iymphatic system. Surgery 49:59 (Jan.) 1961.

8. Bron, K.M., and others: Oil Embolism in lymphangiography, incidence, manifestations and mechanism. Radiology 80:194 (Febr.) 1963.

9. Carvalho, R., and others: La mise en evidence par la radiographic du system Iymphatique chez le vivant. Ann d' Anat. Path. 8:193, 1931.

10. Clementz, B. and Olin, T.: Apparatus for Controlled Infusion of Saline in Angiography and Contrast Medium in Jymphagraphy. Acta Radiol. 55:109 (Febr.) 1961.

11. Collette, J.M.: Lympho raphic experimentale et clinique: description d'une technique d' opefication rediologigue du systeme lymphatique peripherique et du croune gangloinaire iliodelvien., Acta Chir. keIE. 54:607, 1955 (cited by) Mreshchyshym, M.M., and others, Cincer 14:205; 1961 
12. Correll, N., and Fischer, C.: Iymphangioma of the thoracic duct. J A A 182:1136 (Dec.) 1962.

13. Danese, C.: Iymphangiography via subcutaneous injection, Surg. Forum. 11:1169 1960.

14. Davidson, J.K., and others: Radiological Demonstration of Inlarged Retroperitoneal Lymph Nodes.

Lancet 1:1008, 1959.

15. Ditchek, T., and others: Lymphangiography in Normal Subjects. Radiology 80:175 (Febr.) 1963.

16. Dolan, P.A., and Moore, E.B.: Improved technique of lymphangiography. Amer. J. Roentgenol 88:110 (Jul.) 1962.

17. Fischer, H. W.: A Critique of Experimental Iymphography. Acta Radiol. 52:448 (Dec.) 1959.

18. F'ischer, H.W.: Lymphography. Radiology 80:1002 (June) 1963.

19. Fischer, H.W.: A technic for radiography of lymph nodes and vessels. Lab. Investigation. $6: 522$ 1957 .

20. Fischer, H.W., and Zimmerman, G.R.: Roentgenographic Visualization of Lymph Nodes and Lymphatic Channels. Am. J. Roentgenol. 81.517 (March) 1959.

21. Fischer, H.W., and others: Lymphography of the normal adult male. Observations and their relation to the diagnosis of malignant neoplasm. Radiology $78: 397$ (Mar.) 1962 .

22. Funaoka, S.: Der Mechanisms der Lymphbewegung. Arb. a.d. 3d AGT. d. Anat. Inst. d. Kaiserl.Univ. Kyoto, ser. D., HFT 1, 1930. (Cited by) Sheeham and others, Rad. 76,47 (Jan) 1061

23. Gergely, R.: The Significance of Lymphangiography in Surgery. Magy. Sebeszet. 10:246 1957.

24. Gergely, R.: The Roentgen Examination of the Lymphatics in Man. Radiology 71:59 (July) 1959. 
25. Gould, R.J., and Schaffes, B.: The Surgical

Applications of Lymphooraphy., Surgery, Gynecology and Obstetrics. Vo1.114 \#6.0693 Tune 1962

26. Greening, R.R., and Wallace, S.: Further observations in Lymphangiography. Radiol. Clin, $\mathbb{N}$. Amer. 1:157 (Apr.) 1963.

27. Herman, P.G., and others: Roentgen Anatomy of the ilio-pelvic-aortic lymphatic system. Radiology 80:182 (Febr.) 1963.

28. Hreshchyshym, H.M. and Sheehan, F.R.: Lymphangiography in patients with pelvic cancer and lymphomas. Proc. Am. A. Cancer Res. 3:121, 1960.

29. Hreshehyshym, H., and others: Visualization of Retroperitoneal Lymph Nodes. Cancer 14:205, 1961.

30. Jackson, L., and others: The diagnostic value of Iymphangiography. Ann. Int. M. 54:870 (May) 1961.

31. Jacobsson, S., and Johansson, S.: Lymphangiographic changes in Lower limbs with Varicose Veins, Acta. Chir. Scand. 117:346 1959 .

32. Jacobsson, $S_{.}$, and Johansson, S.: Normal Roentgen anatomy of lymph vessels of upper and lower extremities. Acta. Radiol. 51:321 1959.

33. Taindel, E.: Observations on the Iymphatic System in Human Extremities. Medizinishe 24:976 1958.

34. Karrer, F.W. and Musselman, M.W.: The Management of Post-phlebitic syndrome. Annual Convention Nebraska State Medical Association, (Apr. 27, 1969)

35. Kenyon, N.M., and others: Improved Techniques and Results of Lymphagraphy. Surcery, Gynecology and Obstetrics. Vo1 114:6 p677 (Twne) 1962

36. Kinmonth, J.B.: Lymphangiography in clinical surgery and particularly in the treatment of lymphedema. Ann R. Coll. Surgeons England 15:300, 1954. 
37. Kinmonth, J.B., and Taylor, G.W.: Iymphatic circulation in lymphedema. Ann. Surg. 139:129 1954.

38. Kinmonth, J.B., and others: Lymphangiography by by Radiological Methods. J. Fac. Radiologists $6: 131955$.

39. Kinmonth, J.B., and others: Lymphangiography: - technique for Clinical use in lower limb. Brit. M.J. $1: 940 \quad 1055$

40. Malamos, B., and others: Lymphadenography: its uses in haematology. Brit. M.J. 2:1360 1959.

41. Walek, P.: Physiological, Pathophysiological and Anatomical Foundations of Lymphography. Symposium IX. International Cong. Radiol. Munich 1959.

42. Malek, P., and others: Lymphangiography of the Deep Lymphatic System of the Thigh. Acta. Radiol. 51:422 1959 .

43. Mayall, R.C.: Lymphography in Post-phlebitic Syndrome; J. Cardiovascular Surg. 1:176 (Sept.) 1960.

44. Menkes, B.: Rontgendarstellung der Blut-und Lymphgefabe an der Leiche und am Lebenden mittels Umbrathor und Thorotrast. Fortschr. Geb. Rontrenstrahlen 46:571, 1932. (cited by) Hreshchyshyn and others, Cancer 14:2051961

45. Henvillo, L.J., and Añe'J.N: Roentgen Ray visualization of part of lymphatic system. Radiology $23: 327 \quad 1934$.

46. Menville, L.J., and Ané, J.N.: Roentgen Visualization of Lymph nodes in Animals. Prelim. keport. J.A.M.A. 98:1796 (May)21) 1932.

47. Ninth International Congress of Radiology: Symposium on Lymphangiography. 1959.

48. Pfahler, G.E.: A Demonstration of lymphatic drainage Prom the Maxillary Sinuses: Amer. J. Roentgenol. 27:352 (March) 1952. 
49. Pornerantz, M., and others: Clinical Evaluation of Lymphangiography. Surgery 54:270 (July) 1963.

50. Schaffer, B., and others: A Critical Evoluation of Lymphangiography. Radiology 80:917 (June) 1963.

51. Schirger, A. and others: The Problem of Chronic Lymphedema. Heart. Ru11. 11:49-53 (Mav-Tune) 1962

52. Shanbron, E. and Zheutlin, N.: Radiographic Studies of the Lymphatic System. AMA Arch. Intern. Med. 4:589 (Oct.) 1959.

53. Shdanow, D.A.: Rontgenologische Untersuchungsmethoden des Lymphgefabsystems des Menschen und der Tiere. Fortschr. Geb. Rontgenstrahlen 46:680. 1932. (Cited by) Hreshchyshyn and others. Cancer 14:205 1961.

54. Sheeham, R., and others: The Use of Iymphography as a Diagnostic Method. Radiology 76:47 1961.

55. Teneff, S., and Stoppani, F.: E'tude radiographique sur la circulation lymphatique et sur les ganglions lymphatiques. J. de radiol. et d'electrol. 16:533 (Nov.) 1932 .

56. Tziros, D., and others: The Value of Lymphangiography in the diagnosis of Chronic Edema. Surg. Clin. N. America 40:1597 (Dec.) 1960.

57. Viamonte, M., and others: Radiographic-pathologic correlation in the Interpretation of lymphangioadenograms. Radiology 80:903 (June) 1963.

58. Wallace, S., and others: Clinical applications of Iymphangiography. Amer. J. Roentgenol 88:97 (July) 1962.

59. Wallace, S., and others: Lymphangiograms: their diagnostic and therapeutic potential. Radiology $75: 179 \quad 1961$.

60. Wohlgermuth, J.: A Simple Injector for Lymphangiography. Radiol. 80:251 (Febr.) 1963. 
6I. Zheutlin, N., and Shanbron, E.: Contrast visualization of lymph nodes. Radiology 71:702 1958.

62 Zheutlin and others: Radiographic studies of the Iymphatic system. Arch. Intern Med. 104:589 1959.

63. Zolotukhim, A.: Roentgenologic Method of Examination of the Lymphatic system in Man and Animals. Radiology 23:455 (oct) 1934 . 